\title{
The Statistical Relationship between Upslope Flow and Rainfall in California's Coastal Mountains: Observations during CALJET
}

\author{
Paul J. Neiman and F. Martin Ralph \\ NOAA/Environmental Technology Laboratory, Boulder, Colorado \\ A. B. WHITE \\ Cooperative Institute for Research in Environmental Sciences, and NOAA/Environmental Technology Laboratory, Boulder, Colorado \\ D. E. KINGSMILL \\ Desert Research Institute, Reno, Nevada \\ P. O. G. PERSSON \\ Cooperative Institute for Research in Environmental Sciences, and NOAA/Environmental Technology Laboratory, Boulder, Colorado
}

(Manuscript received 29 January 2001, in final form 27 November 2001)

\begin{abstract}
The California Landfalling Jets Experiment (CALJET) was carried out during the winter of 1997/98, in part to study orographic rainfall in California's coastal mountains using coastal wind profilers. This observational study statistically links hourly rainfall rates observed by tipping-bucket rain gauges in California's quasi-linear coastal mountains to the hourly averaged upslope component of the flow measured by coastal wind profilers immediately upstream. Vertical profiles of the linear correlation coefficient of upslope flow versus rain rate are calculated on a case-by-case basis, for all cases containing a low-level jet (LLJ), and for the winter season of 1997/98. These correlation coefficient profiles show a direct relationship between the magnitude of the upslope flow impacting the coast and the magnitude of the rain rate in the downstream coastal mountains. Maximum correlation coefficients are as large as 0.94 in some individual cases, 0.75 for a composite of LLJ cases, and 0.70 for the winter season.

Using three locations with differing coastal terrain characteristics, it is found that the layer of upslope flow that optimally modulates orographic rainfall is near mountaintop, that is, about $1 \mathrm{~km}$ above mean sea level for California's coastal ranges. This height also corresponds to the mean altitude of landfalling LLJs observed by the coastal profilers. The correlation coefficient in this layer is largest when the rain rates are used from the coastal mountain sites rather than from the coastal sites, thus further highlighting the physical connection between upslope flow and orographic rainfall in the coastal mountains. The presence of shallow, terrain-blocked flow modulates the correlation coefficient profiles below mountaintop, such that the low-level flow at the coast is poorly correlated with rain rates observed in the coastal mountains. However, cases without significant blocking retain relatively large correlation coefficient values below mountaintop.

Landfalling LLJs produce the largest enhancement of upslope flow at the altitude of the LLJ, despite the existence of terrain-modified flows below mountaintop during some LLJ events. The steepest increase in rain rate for a given increase in upslope flow also occurs at jet level, as does the largest correlation coefficient of upslope flow versus rain rate. Therefore, the upslope-induced orographic rain-rate response associated with landfalling LLJs is largest $\left(2.55 \mathrm{~mm} \mathrm{~h}^{-1}\right)$ and statistically most robust near the altitude of those LLJs.
\end{abstract}

\section{Introduction}

During a typical winter, many mountain ranges of the western United States are inundated with copious amounts of orographically enhanced precipitation. Per-

Corresponding author address: Paul J. Neiman, NOAA/Environmental Technology Laboratory, Mail Code R/ET7, 325 Broadway, Boulder, CO 80305.

E-mail: paul.j.neiman@noaa.gov haps the largest of these ranges is the Sierra Nevada of California, reaching an altitude of more than $4 \mathrm{~km}$ above mean sea level (MSL) and extending horizontally for over $600 \mathrm{~km}$. Because California depends on runoff from the Sierra for its water supply and power generation, numerous investigators (e.g., Myers 1962; Colton 1976; Heggli and Rauber 1988; Meyers and Cotton 1992; Pandey et al. 1999) have studied wintertime orographic precipitation associated with this lofty and 
lengthy mountain range. Though far less dramatic than the Sierra, California's coastal mountain ranges also generate significant orographic precipitation. These modest ranges are typically less than $100 \mathrm{~km}$ long and extend upward to only about 500-1500 m MSL, but they can generate orographically induced floods during the landfall of winter storms, incurring millions of dollars in property damage and fatalities (e.g., NOAA 1982; NCDC 1995, 1998). As California's coastal population continues to blossom, orographic floods generated by these mountains pose an increasing threat. Motivated by this threat, the California Landfalling Jets Experiment (CALJET; Ralph et al. 1998, 1999) was carried out during the winter of 1997/98. CALJET's experimental objectives led to the offshore deployment of a National Oceanic and Atmospheric Administration (NOAA) P-3 research aircraft and the coastal-zone deployment of an array of wind profilers that measure winds with $100-\mathrm{m}$ resolution from near the surface up to $\sim 4 \mathrm{~km}$, well above the highest coastal terrain.

Wintertime precipitation in mountainous terrain is typically enhanced by one of two orographic mechanisms: the low-level growth of falling hydrometeors via the "seeder-feeder" process, or the development of convective precipitation elements via the release of potential instability. In the seeder-feeder mechanism, orographic uplift generates or enhances low-level feeder clouds with high liquid water content that cap the mountains. The enhanced liquid water content in the feeder clouds leads to rapid and efficient low-level growth of seeder precipitation falling into the feeder clouds from above (e.g., Bergeron 1965; Storebø 1976; Bader and Roach 1977; Gocho 1978; Browning 1980; Carruthers and Choularton 1983). The release of potential instability is realized when air parcels are orographically lifted to the level of free convection (e.g., Browning et al. 1974; Hill 1983). The heaviest orographic rains often occur within potentially unstable warm sectors of extratropical cyclones that do not contain significant largescale lift, because the potential instability is preserved until acted upon by orographic lift (e.g., Lowndes 1968; Browning et al. 1974).

Because both of these mechanisms involve orographically forced ascent, it is commonly known that moist flow ascending a mountain barrier (i.e., upslope flow) will typically enhance precipitation along the windward slope of that barrier, and that the amount of precipitation that falls is related to the magnitude of the upslope flow. The dependence of orographic precipitation on upslope flow is borne out in a variety of orographic precipitation modeling studies (e.g., Collier 1975; Bell 1978; Rhea 1978; Alpert and Shafir 1989, 1991; Sinclair 1994) that show orographic precipitation and its mesoscale distributions are generated largely by horizontal flow impinging upon windward mountain slopes. A variant of the Rhea (1978) orographic precipitation model has been coupled with operational three-dimensional model output to forecast wintertime precipitation across the mountainous western United States. These precipitation forecasts are based on the magnitude of the predicted flow (at 50-mb increments, from 1000 to $450 \mathrm{mb}$ ) aligned along the wind direction at $700 \mathrm{mb}$ impinging upon the mountain barrier, when sufficient moisture is present. Previous observational studies have also shown a primary dependence of orographic precipitation on the upslope component of the flow (e.g., Nord $\varnothing$ and Hjortnæs 1966; Hill et al. 1981; Hill 1983; Pandey et al. 1999).

Clearly, the relationship between upslope flow and orographic precipitation is modulated on a case-by-case basis by a variety of factors, including the ambient thermodynamic stratification and resulting dynamics of the atmospheric flow over or around orographic obstacles, the availability of moisture, latent heat release, the efficiency and timescale of hydrometeor generation, and the downstream advection of those hydrometeors (e.g., Sawyer 1956; Smith 1979). Nevertheless, the modeling results cited above suggest that, on the simplest level, orographic precipitation is the product of moist, terrainfollowing flow. Therefore, given the availability of CALJET wind profiler data, it must be asked if a meaningful statistical relationship exists between high temporal resolution $(1 \mathrm{~h})$ observations of upslope flow and orographic rainfall within winter storm environments, irrespective of these other factors? If so, is this relationship impacted by differing terrain characteristics and weather regimes, and by wind measurements at different heights? Observational studies by Nord $\varnothing$ and Hjortnæs (1966) and Hill et al. (1981) partially address the first question. Nord $\varnothing$ and Hjortnæs show a linear dependence of winter precipitation in Norway's mountains on surface geostrophic upslope flow at the coast using data over a multiyear span. However, their data are temporally coarse ( $\geq 12-\mathrm{h}$ resolution), and their study does not consider the onshore flow above the often-blocked boundary layer along Norway's coast. Hill et al. show a direct relationship between the magnitude of the lowlevel onshore flow measured by rawinsondes $600 \mathrm{~m}$ above the coast of Wales and wintertime orographic rain-rate enhancement in the shallow hills downwind. However, they used only 14 data points of wind speed versus rain-rate enhancement, thus limiting the statistical significance of their findings. These data points were based on events ranging from 1.7 to $10.0 \mathrm{~h} \mathrm{du}$ ration, thus introducing additional uncertainty to their results, since the magnitude of rain rate is typically inversely proportional to the duration of the event. They applied a power regression fit to their data, which is not physically plausible in strong onshore flow where the inferred rain rate becomes unrealistically large. The observational study by Pandey et al. (1999) took an additional step by considering the relationship between the horizontal moisture flux orthogonal to the Sierra and orographic precipitation. However, their study is based on data taken only at mandatory levels between 850 and $300 \mathrm{mb}$ on a daily basis. 
To more fully address the questions posed above, we applied a linear regression analysis technique to $\sim 1000$ hourly CALJET wind-profiler wind profiles taken along California's coast and companion rain gauge observations in the downstream quasi-linear coastal mountains during landfalling winter storms. This approach provided the opportunity to adequately evaluate the simple linear relationship between coastal upslope flow in the lowest $4 \mathrm{~km}$ of the troposphere and mountain rain rate at three locations with differing coastal terrain characteristics. Unlike earlier upper-air observational studies of orographic precipitation that used either a small sample of multihour wind data at a single level or used daily moisture-flux calculations at coarsely spaced multiple levels for high mountain barriers, our study utilizes a continuous stream of $\sim 100$-m-vertical-resolution hourly profiles of horizontal wind to determine the layer of upslope flow that optimally modulates rain rates in California's shallow coastal mountain ranges. As we will show, this layer is situated well above the surface. On the other hand, it is considerably lower than that used for obtaining the direction of flow in Rhea's (1978) operational orographic precipitation model, and it resides beneath the lowest level used by Pandey et al. (1999) to observationally assess the upstream impacts on orographic precipitation in the high Sierra. We also utilized the profiler observations to explore the impacts of terrain-modified lower-tropospheric flows on rainfall behavior in the coastal zone, and to investigate the modulation of mountain rain rates by landfalling low-level jets where low-level moisture tends to be concentrated. Unfortunately, wind profilers lack the thermodynamic and moisture information needed to comprehensively address all aspects of orographic precipitation enhancement. Nevertheless, our profiler-based study follows a primary recommendation offered by the Mountain Meteorology Prospectus Development Team of the United States Weather Research Program (Smith et al. 1997), namely, to explore and develop techniques for improved observations of orographic precipitation. Like CALJET, the Mesoscale Alpine Programme (MAP; Bougeault et al. 2001) explored orographic precipitation; however, it focused on the more complex alpine environment and thus required an emphasis on three-dimensional aspects of the problem that were not a central issue in the CALJET experiment.

\section{Observing systems and basic data processing}

During its field phase in the winter of 1997/98, the CALJET program deployed and utilized an extensive suite of mobile and anchored observing platforms across its experimental domain over the data-sparse eastern Pacific Ocean and in California (Ralph et al. 1998). This suite included a NOAA P-3 research aircraft (e.g., Jorgensen 1984; Jorgensen and Smull 1993) that documented tropospheric conditions offshore of California and an array of 12 915-MHz radar wind profilers (Eck-

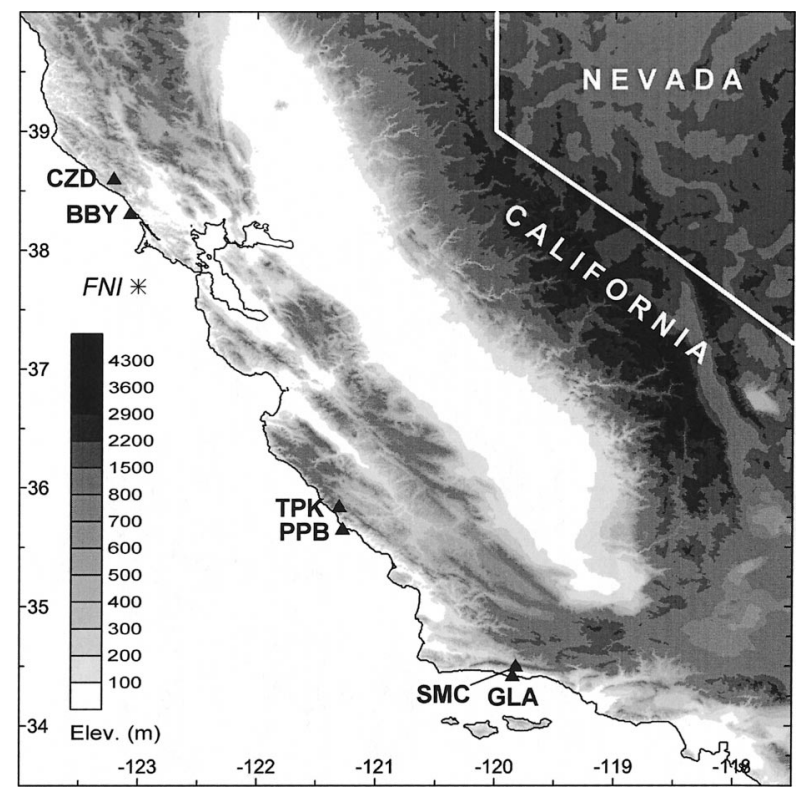

FIG. 1. Smoothed terrain base map of CA showing gray-shaded terrain $(\mathrm{m})$, the three wind profiler-rain gauge observing couplets $(\mathbf{\Delta})$, and the offshore profiler at FNI $(*)$.

lund et al. 1988) deployed along California's coast by NOAA's Environmental Technology Laboratory (ETL). These profilers routinely provided hourly averaged vertical profiles of horizontal wind velocity from $\sim 0.1$ to $4.0 \mathrm{~km}$ above ground with $100-\mathrm{m}$ vertical resolution in clear, cloudy, and precipitating conditions. The hourly averaged winds were calculated from measurements made about every $6 \mathrm{~min}$. The subhourly measurements and hourly averaged winds were objectively edited using the vertical-temporal continuity method of Weber et al. (1993). Wind data measured by a collocated surface meteorological tower at each profiler extended the hourly wind profiles down to the surface. Each profiler site was also equipped with a tipping-bucket rain gauge that measured rainfall every 2 min with 0.01 -in. $(\sim 0.25$ $\mathrm{mm})$ resolution. Two-minute surface measurements of temperature, moisture, and pressure were also taken at each site. Another key component of this observational suite was California's operational ALERT (automated local evaluation in real time) network of $\sim 900$ rain gauges that provided measurements of rainfall with 0.04 -in. $(\sim 1.0 \mathrm{~mm})$ resolution as frequently as every 15 min. A brief description of this heterogeneous network is provided in Mendell (1992). All rain-rate measurements were susceptible to wind-speed-dependent undercatchment errors that can range from $2 \%$ to as much as 20\% (e.g., Yang et al. 1998; Groisman et al. 1999).

Four of these profilers and collocated rain gauges, plus two additional rain gauges from the ALERT network, composed three observing couplets in northern, central, and southern California that are the centerpiece of this study (Figs. 1 and 2, Table 1). Each couplet 

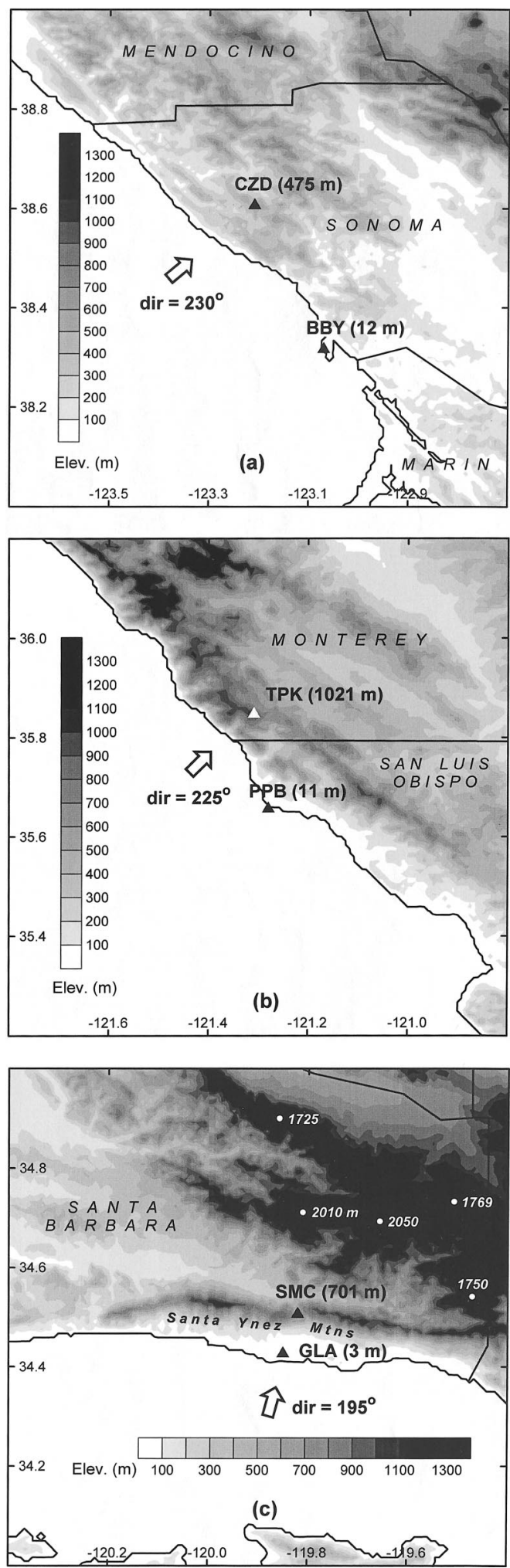

FIG. 2. Smoothed terrain base maps ( $m$, gray shading) of the (a) northern, (b) central, and (c) southern wind profiler-rain gauge observing couplets. The site elevations (MSL) and the vectors portraying the flow direction most nearly perpendicular to the mountain barrierat each couplet are also shown. Each coastal site (BBY: Bodega Bay; consisted of a coastal site and a mountain site that were separated by $\sim 10-30 \mathrm{~km}$. The coastal sites ranged from 3 to $12 \mathrm{~m}$ MSL and the mountain sites were at 475$1021 \mathrm{~m}$ MSL. The northern couplet had a wind profiler at each site, and the central and southern couplets each had an ALERT rain gauge at their mountain site. Our study also utilized data from a fifth wind profiler, located on the Farollon Islands (FNI in Fig. 1), to measure tropospheric winds $\sim 70 \mathrm{~km}$ offshore of the northern couplet.

Because the profilers were configured to routinely provide quality-controlled wind velocity data on an hourly averaged basis, and based on the rationale described in section $b$ of the appendix, the analyses presented in the body of this study utilize hourly averaged wind-profiler and rain gauge data. The time series of these hourly wind velocity data at each range gate (including surface winds), and hourly rain-rate data, were subjected to one pass of a 1-2-1 temporal Hann filter to obtain a mean characterization of the winds and rainfall while reducing measurement uncertainties. This filtering procedure removed the 2-delta (i.e., 2-h) temporal variability, a time interval that is much smaller than the duration of the shortest-lived rain events treated in this study (i.e., 15 and $8 \mathrm{~h}$ for the case-study and winterseason events, respectively).

\section{Methodology for deriving correlation coefficient profiles of upslope flow versus rain rate}

\section{a. Basic theory}

To establish the statistical relationship between maritime air ascending a coastal mountain barrier and rainfall rates observed in those mountains, we first adapted the formulation for rain rate derived in Alpert (1986). This adaptation essentially equates the upward flux of water vapor with rain rate $R$ for steady-state conditions, thus yielding

$$
R \approx \overline{\rho q}\left(\mathbf{V} \cdot \nabla Z_{s}\right),
$$

where $\bar{\rho}$ and $\bar{q}$ are the layer-mean air density and water vapor mixing ratio, respectively, and $\mathbf{V} \cdot \nabla Z_{s}$ represents the horizontal wind flowing over the mean mountain slope whose height is defined as $Z_{x}$. Eq. (1) assumes rain rate is minimally impacted by evaporation, orographically forced ascent is appreciably larger than synoptic ascent, and hydrometeor generation is instantaneous and $100 \%$ efficient. While the impact of evaporation was minimal for the rain events analyzed in this paper (i.e., the lower and middle troposphere were es-

$\leftarrow$

PPB: Piedras Blancas; and GLA: Goleta) hosted a 915-MHz wind profiler, and each nearby mountain site (CZD: Cazadero; TPK: Three Peaks; and SMC: San Marcos Pass) hosted a tipping-bucket rain gauge. CZD also had a wind profiler. Counties are labeled. Selected mountain elevations in (c) are shown in white. 
TABLE 1. Site information and mean terrain characteristics of the three wind-profiler-rain gauge observing couplets in CA. Each wind profiler operated at a frequency of $915 \mathrm{MHz}$ and was accompanied by a tipping-bucket rain gauge.

\begin{tabular}{lccccccccccc}
\hline \hline & $\begin{array}{c}\text { Coastal } \\
\text { profiler } \\
\text { site }\end{array}$ & $\begin{array}{c}\text { Lat } \\
\left({ }^{\circ} \mathrm{N}\right)\end{array}$ & $\begin{array}{c}\text { Lon } \\
\left({ }^{\circ} \mathrm{W}\right)\end{array}$ & $\begin{array}{c}\text { Coastal } \\
\text { elevation } \\
(\mathrm{m} \mathrm{MSL})\end{array}$ & $\begin{array}{c}\text { Mountain } \\
\text { rain gauge } \\
\text { site }\end{array}$ & $\begin{array}{c}\text { Lat } \\
\left({ }^{\circ} \mathrm{N}\right)\end{array}$ & $\begin{array}{c}\text { Lon } \\
\left({ }^{\circ} \mathrm{W}\right)\end{array}$ & $\begin{array}{c}\text { Mountain } \\
\text { elevation } \\
(\mathrm{m} \mathrm{MSL})\end{array}$ & $\begin{array}{c}\text { Mean } \\
\text { barrier } \\
\text { orientation }\end{array}$ & $\begin{array}{c}\text { Mean } \\
\text { barrier } \\
\text { height } \\
(\mathrm{m})\end{array}$ & $\begin{array}{c}\text { Mean } \\
\text { barrier } \\
\text { steepness } \\
(\delta h / \delta s)^{\mathrm{c}}\end{array}$ \\
\hline Northern & $\mathrm{BBY}$ & 38.31 & 123.07 & 12 & $\mathrm{CZD}^{\mathrm{a}}$ & 38.61 & 123.21 & 475 & $140^{\circ}-320^{\circ}$ & 650 & 0.08 \\
Central & PPB & 35.66 & 121.28 & 11 & $\mathrm{TPK}^{\mathrm{b}}$ & 35.85 & 121.31 & 1021 & $135^{\circ}-315^{\circ}$ & 1150 & 0.16 \\
Southern & GLA & 34.43 & 119.85 & 3 & SMC $^{\mathrm{b}}$ & 34.51 & 119.82 & 701 & $105^{\circ}-285^{\circ}$ & 1050 & 0.19 \\
\hline
\end{tabular}

a A 915-MHz wind profiler was also situated at this site.

b ALERT rain gauge.

c The mean barrier steepness or slope is a bulk value that was determined by going from the initial significant rise in terrain near the coast upward to the mountain site along the vector oriented perpendicular to the mean barrier.

sentially saturated in each of these storms), this is not necessarily the case for all rain events in California's coastal mountains. In addition, the impact of evaporation can be significant in arid mountainous regions. Regarding the second assumption, while it is generally true that synoptic ascent is much weaker than orographically forced ascent, some of the events analyzed in this study were associated with landfalling fronts that contained narrow bands of heavier rainfall. In these narrow bands, the magnitude of mesoscale ascent can approach that of orographically forced ascent, especially if the upslope component of the flow is simultaneously weak. Hence, these transient mesoscale features introduced uncertainty in the application of Eq. (1). Perhaps the largest potential source of error utilizing Eq. (1) is tied to microphysics. The efficiency of hydrometeor generation for orographic precipitation is often less than $100 \%$ and is scaled to mountain height (e.g., Myers 1962; Elliot and Hovind 1964; Browning et al. 1975). Elliot and Hovind (1964) show an efficiency of only $17.4 \%$ in stably stratified flow impacting California's Santa Ynez coastal mountains.

For simplicity, our three observing couplets were chosen because the nearby coastal mountains were quasitwo-dimensional. Hence, assuming two-dimensionality, Eq. (1) reduces to:

$$
R \approx \overline{\rho q}(U \partial h / \partial s)
$$

where $U \partial h / \partial s$ is the orographically forced ascent associated with the barrier-perpendicular (i.e., upslope) component of the flow $(U)$ ascending the two-dimensional barrier slope $(\partial h / \partial s)$. Because thermodynamic soundings were not launched frequently during CALJET, this study was not able to obtain the layer-mean air density and water vapor mixing ratio profiles with the same rapid temporal resolution as the wind profiler observations (i.e., at least hourly). Therefore, we statistically examined the linear proportionality that relates the upslope component of the flow to rainfall rate:

$$
R \propto U \partial h / \partial s,
$$

where the terrain in the vicinity of each couplet possesses a characteristic steepness (Table 1). Measurements of hourly averaged upslope flow were obtained by the profilers at the coastal sites, and hourly rain rates were measured there and in the high terrain immediately downstream of the profilers.

\section{b. Determining the upslope component of the flow}

The first step toward calculating the hourly averaged upslope component of the flow from wind profiler observations was to assess the two-dimensional terrain orientation at each of the three observing couplets. This exercise was performed based on the detailed base maps shown in Figs. 2a-c. We subjectively chose the dominant quasi-linear terrain orientation possessing long-axis continuity of $\sim 30-60 \mathrm{~km}$ in the vicinity of each couplet. These orientations are summarized in Table 1 and yield barrier-perpendicular directions of $230^{\circ}, 225^{\circ}$, and $195^{\circ}$ at the northern, central, and southern couplets, respectively (Fig. 2). Note that the direction at the southern couplet is oriented orthogonal to the abrupt and highly two-dimensional Santa Ynez Mountains just north of Goleta, California (GLA) rather than perpendicular to the taller but less organized mountains north of San Marcos Pass, California (SMC) (Fig. 2c). Vertical profiles of upslope flow $U(z)$ at each observing couplet were then calculated from the wind velocity profiles measured by that couplet's coastal wind profiler, based on the magnitude of the flow aligned perpendicular to the barrier.

\section{c. Rationale for site selection and case selection}

Correlation analyses of upslope flow measured by the coastal profilers versus rain rate observed in the downstream coastal mountains were performed at each of the three observing couplets, as will be described in section $3 \mathrm{~d}$. The three couplets possessed differing physiographic attributes (Fig. 2; Table 1) and were chosen to assess the impact of these differences on the correlation results. Though the mean barrier orientation is similar at the northern and central couplets, the barrier is taller, steeper, and more two-dimensional at the central couplet. Moreover, though the height, steepness, and two-dimensional character of the terrain are similar at the central and southern couplets, the barrier orientations are 
markedly different. It should be noted that detailed differences in the siting of the mountain rain gauges relative to the local mountain peaks (e.g., the central gauge was near the crest of the mesoscale terrain while the southern gauge was well below) could impact our statistical results.

The correlation analyses are divided into case-study and winter-season perspectives. The winter-season methodology and results are presented in section 5. The case-study approach is described here, and the results from the seven cases listed in Table 2 are presented in section 4. Each case was characterized by substantial total rainfall at the mountain site (ranging from 42.03 to $210.17 \mathrm{~mm}$ ) and a duration of at least $15 \mathrm{~h}$. Highamplitude, long-lasting cases were chosen to increase the likelihood that significant rainfall was generated by orographic ascent, and to provide statistically significant correlation analyses based on a sufficient sample size. Each case commenced shortly (i.e., $<2$ h) before rain started falling at the mountain site and ended shortly after the rain ended at the mountain site, with two exceptions. The end of the unblocked case at the central couplet coincided with a major change in the synoptic rainfall distribution at that couplet (i.e., the onset of intense cold-frontal rainfall), and the end of the blocked case at the southern couplet coincided with a floodinginduced failure of the coastal wind profiler.

\section{d. Correlation coefficient analysis}

Because Eq. (3) contains a linear proportionality between upslope flow $U$ and rain rate $R$, a least squares linear regression fit was applied to time series of $U$ observed at the altitude of each wind-profiler range gate and corresponding time series of $R$ measured in the downstream coastal mountains, thus yielding a vertical profile of correlation coefficient $r(z)$ for each case. These correlation profiles extended from the surface to $4 \mathrm{~km}$ MSL, and they are based on routinely available, hourly averaged wind-profiler measurements of upslope flow in 500-m-thick layers (and at the surface) and hourly observations of rainfall; wind velocities that contained a downslope component (i.e., $U<0 \mathrm{~m} \mathrm{~s}^{-1}$ ) were excluded from the correlation analysis at that height. The rationale for utilizing these temporal and vertical averages is provided in the appendix. The interpretation of these correlation results is subject to inaccuracies due to the working assumptions described in section $3 \mathrm{a}$ and because 1) the mountain barrier is not fully two-dimensional, 2) it takes a finite amount of time (though typically less than $\sim 15 \mathrm{~min}$ ) for conditions to propagate from the coastal profilers to the mountain rain gauges, 3 ) the profiler-rain gauge couplets are not necessarily perfectly aligned with the mean flow, and 4) the wind and precipitation fields may exhibit spatial inhomogeneities. Nevertheless, our linear methodology is supported by the observational results of Nord $\varnothing$ and Hjortnæs (1966). They explored the dependence of mountain precipitation in Norway on the upslope component of the surface geostrophic flow and found that most of the explained variance between these variables was linear.

Though our correlation technique is based on a linear dependence of rain rate on upslope flow, thermodynamic factors such as moisture, static stability, and potential instability can also affect the rain rate. Because we did not launch frequent thermodynamic soundings during CALJET with the same finescale temporal resolution (i.e., $\sim 1 \mathrm{~h}$ ) as the wind-profiler observations, this study could not fully link these factors to the rain rates observed in the coastal mountains. A bivariate linear correlation analysis of upslope flow and moisture versus rain rate was carried out based on Eq. (2), but we were forced to use surface measurements of hourly water vapor mixing ratio rather than tropospheric values. The correlation analyses to be presented in this paper were not improved by the inclusion of the surface moisture data (not shown), either because the surface measurements were unrepresentative of conditions aloft or because the low-level moisture flux affecting the orographic precipitation was not greatly affected by variations in low-level mixing ratios during the rain events. This latter hypothesis is supported by the fact that the magnitude of low-level upslope flow can range between 0 and $20 \mathrm{~m} \mathrm{~s}^{-1}$ during individual rain events whereas concurrent surface mixing ratios vary by less than $25 \%$ (typically between about 8 and $10 \mathrm{~g} \mathrm{~kg}^{-1}$; not shown), that is, the moisture flux is determined largely by the magnitude of the upslope flow. The strength of the ambient static stability can modulate the magnitude and direction of the low-level flow as it approaches the orography (e.g., Smith 1979; Pierrehumbert and Wyman 1985; Smolarkiewicz and Rotunno 1990), which can then modify the precipitation distributions in and near the high terrain (e.g., Dunn 1987; Peterson et al. 1991; Sinclair et al. 1997; Doyle 1997; Yu and Smull 2000). A statistical connection between terrain-modified lowlevel flows and rain rate is offered in this paper. Static stability and potential instability are intimately coupled, though adequate exploration of the statistical relationship between potential instability and rain rate was not possible because of a lack of supporting thermodynamic data with high temporal resolution.

\section{Orographic precipitation enhancement: Case- study examples}

Based on the correlation methodology described above, this section explores occurrences of orographic precipitation enhancement observed at the three couplets using a case-study approach. A case study is presented from each couplet for unblocked and blocked conditions. We also explore the statistical relationship between upslope flow and rain rate for a case at the northern couplet that exhibited complex flow characteristics. These seven cases are listed in Table 2. 
TABLE 2. Time windows of the seven case studies and winter-season databases for the three observing couplets. Rainfall characteristics of these case studies, and of the winter season for each couplet, are also shown. The values labeled "WS" in parentheses are the coupletspecific rain ratios based on the winter-season data. The value labeled "avg WS" in parentheses is an average of the winter-season rain ratios from the three couplets.

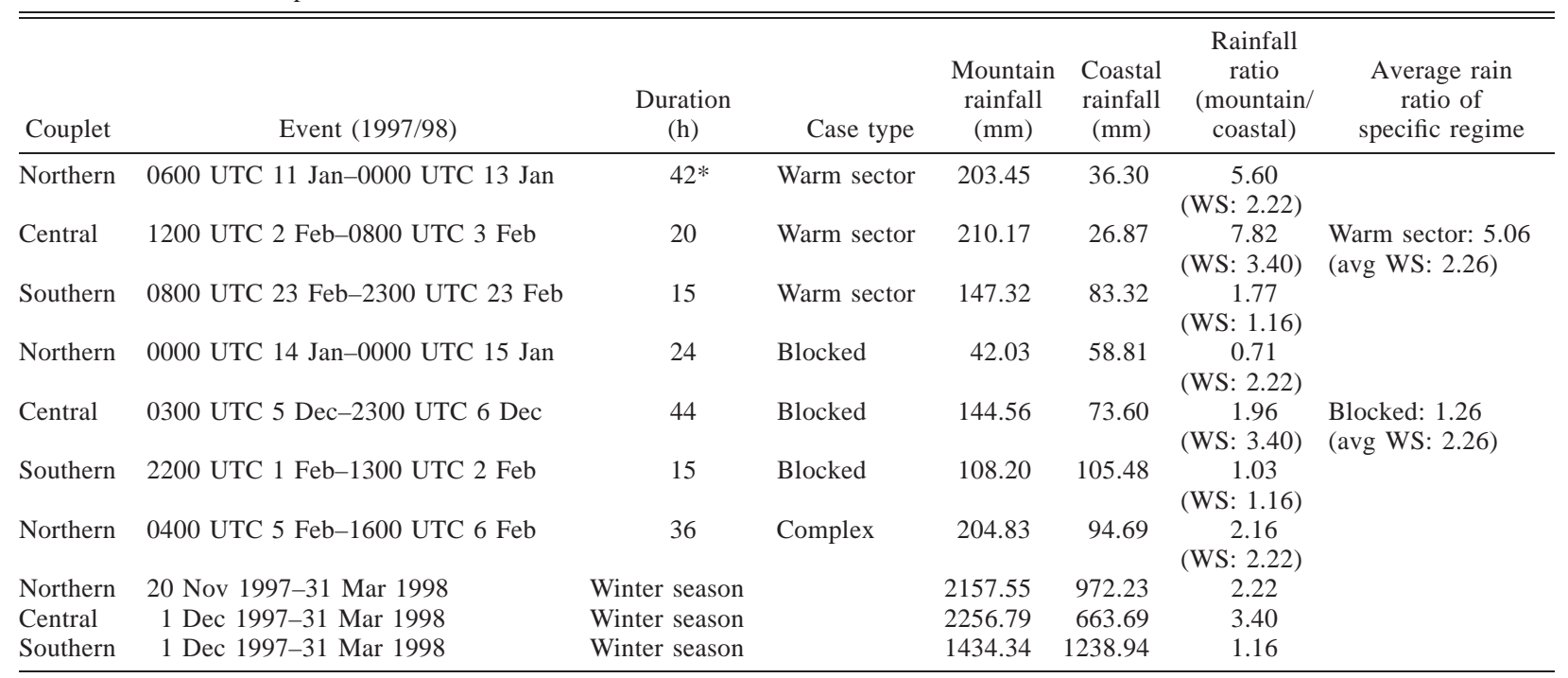

* The analysis in section b of the appendix utilizes a 33-h subset within this temporal window, from 1200 UTC 11 Jan to 2100 UTC 12 Jan 1998.

\section{a. Unblocked cases}

The unblocked cases possessed the following common attributes: ${ }^{1} 1$ ) each event occurred primarily within the moist warm sector of a transient extratropical cyclone where the synoptic forcing was weak, 2) most of the rain at each mountain site fell within the warm sector, and 3) the low-level flow was not strongly deflected by the terrain. The rainfall ratio between the mountain and coastal sites at each couplet was considerably greater for each unblocked event than for the winter season (Table 2), thus highlighting the importance of orographic rainfall enhancement in California's coastal mountains in these conditions. The release of potential instability by orographically forced ascent likely contributed to this large enhancement, since maritime warm sectors frequently possess low- to midlevel potential instability that is triggered by orographic lift, thus producing heavy mountain rains (e.g., Lowndes 1968; Browning et al. 1974; Hill and Browning 1979; Hill 1983). In situ observations from NOAA's P-3 research aircraft offshore of the central couplet on 2 February 1998 (not shown) confirmed the presence of potential-instability laminae in the warm sector below $\sim 4 \mathrm{~km}$ MSL.

The time-height section of hourly averaged winds and upslope isotachs from the northern couplet at BBY (Fig. 3a) shows exclusively upslope-component flow for the duration of the 42-h event. The strongest low-level upslope flow occurred in two periods within the warm

\footnotetext{
${ }^{1}$ These attributes were determined by interpreting data from wind profilers, rain gauges, the NOAA P-3 research aircraft, rawinsondes, ships, buoys, surface stations, and satellites.
}

sector: following the warm-frontal passage and preceding the cold front. The warmest equivalent potential temperature $\theta_{e}$ at the surface was observed in the moist warm sector (Fig. 3a, bottom panel). Diverging time series traces of accumulated rainfall at Cazadero, California (CZD) and Bodega Bay, California (BBY; Fig. 3a) highlight the orographic rainfall enhancement that occurred in the coastal mountains. Coastal measurements of the layer-mean upslope flow at BBY between 0.6 and $1.1 \mathrm{~km}$ MSL at each hour were combined with the corresponding mountain rain-rate observations at CZD into a scatterplot diagram (Fig. 3b). This diagram, which represents the layer of maximum correlation coefficient for this case, reveals a correlation coefficient of 0.880 and a linear regression slope of 0.91. Applying this same regression technique to each 500-m layer (and to the surface) of the 42 wind profiles yields the correlation profile in Fig. 3c. This profile shows a robust correlation between the upslope flow in the lower troposphere at BBY and the rain rate in the coastal mountains at CZD. The correlation is maximized just above mountaintop (i.e., $\sim 0.65 \mathrm{~km} \mathrm{MSL}$ ) and then decreases significantly with height above $\sim 1.2 \mathrm{~km}$ MSL, thus revealing that the rain rate was optimally related to the magnitude of the upslope flow slightly above mountaintop. The surface flow was also a useful indicator of mountain rain rate (i.e., a surface correlation coefficient of 0.656).

At the central couplet, the Piedras Blancas, California (PPB) profiler observed the temporal descent of warmfrontal, upslope-component shear from $\sim 3 \mathrm{~km}$ MSL at 1200 UTC 2 February to the surface $6 \mathrm{~h}$ later, followed 

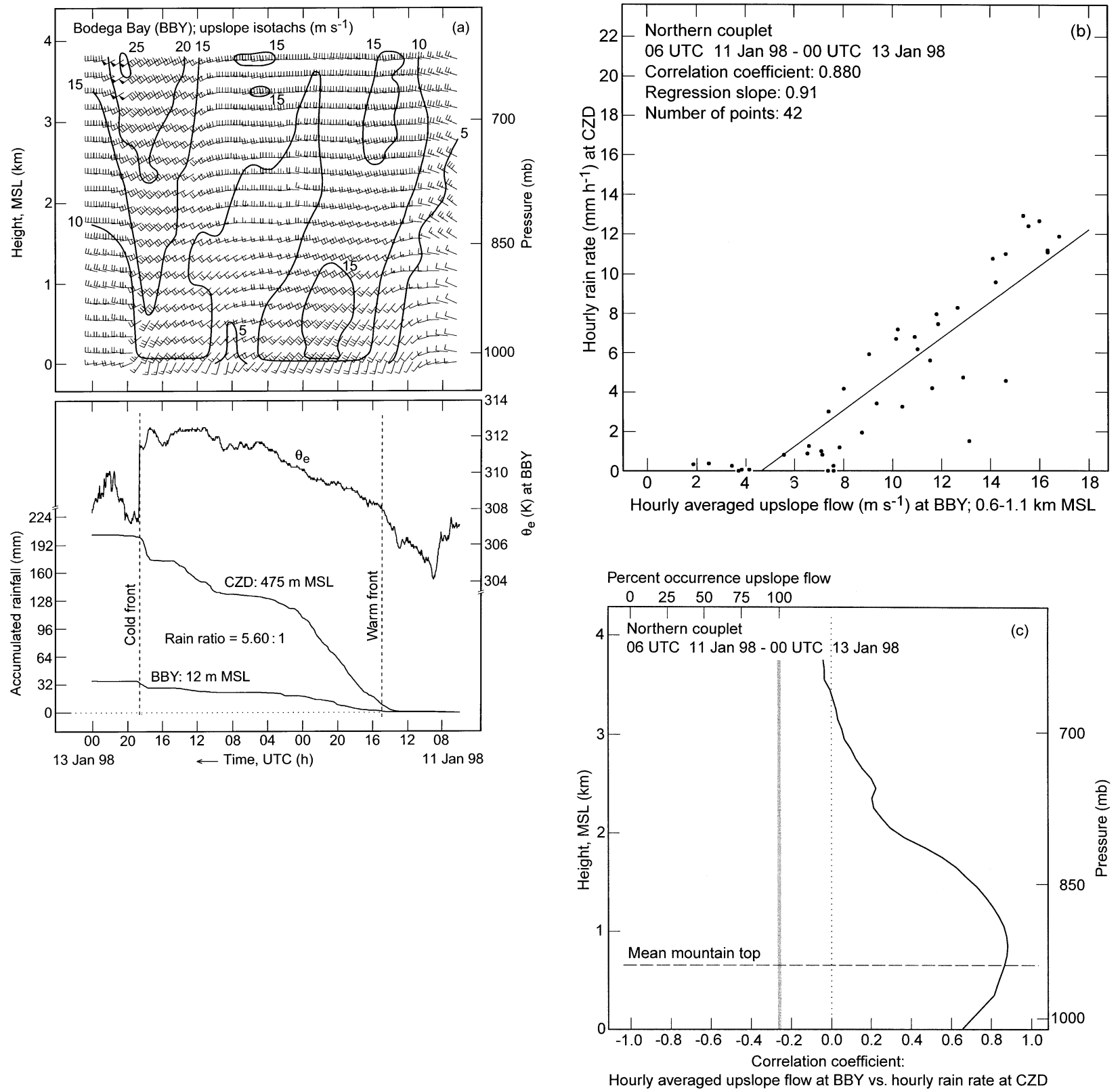

FIG. 3. (a) Time-height section of hourly averaged horizontal wind profiles (flags $=25 \mathrm{~m} \mathrm{~s}^{-1}$, full barbs $=5 \mathrm{~m} \mathrm{~s}^{-1}$, half-barbs $=2.5 \mathrm{~m}$ $\mathrm{s}^{-1}$ ) and upslope-component isotachs at BBY (top panel), and time series traces of surface equivalent potential temperature $\theta_{e}$ at BBY and accumulated rainfall at BBY and CZD (bottom panel), between 0600 UTC 11 Jan and 0000 UTC 13 Jan 1998. (b) Scatterplot of hourly averaged, layer-mean (0.6-1.1 km MSL) upslope flow at BBY vs hourly rain rate at CZD for the period shown in (a). The linear regression fit is shown. (c) Vertical profile of linear correlation coef (black) based on hourly averaged profiles of upslope flow at BBY vs hourly rain rate at CZD for the period shown in (a). The vertical profile of percent occurrence of upslope flow is also shown (gray shade), as is the mean mountaintop height of the neighboring coastal mountains. The vertical pressure coordinate in (a) and (c), and in subsequent figures, is based on a standard atmosphere.

by enhanced upslope flow in the high- $\theta_{e}$ warm sector (Fig. 4a). A nearly 8:1 ratio in rainfall between Three Peaks, California (TPK) and PPB (Fig. 4a) highlights the orographic rain enhancement that occurred during this event. The scatterplot diagram of upslope flow at PPB versus rain rate at TPK for the layer of maximum correlation (Fig. 4b) yields a correlation coefficient of
0.939 and a regression slope of 1.19. This slope is larger than that at the northern couplet, a result that is physically consistent with the fact that the terrain is steeper at the central couplet (Table 1), that is, a larger fraction of the upslope flow is deflected vertically to produce heavier rain at the central couplet. The vertical profile of correlation coefficient for upslope flow at PPB versus 

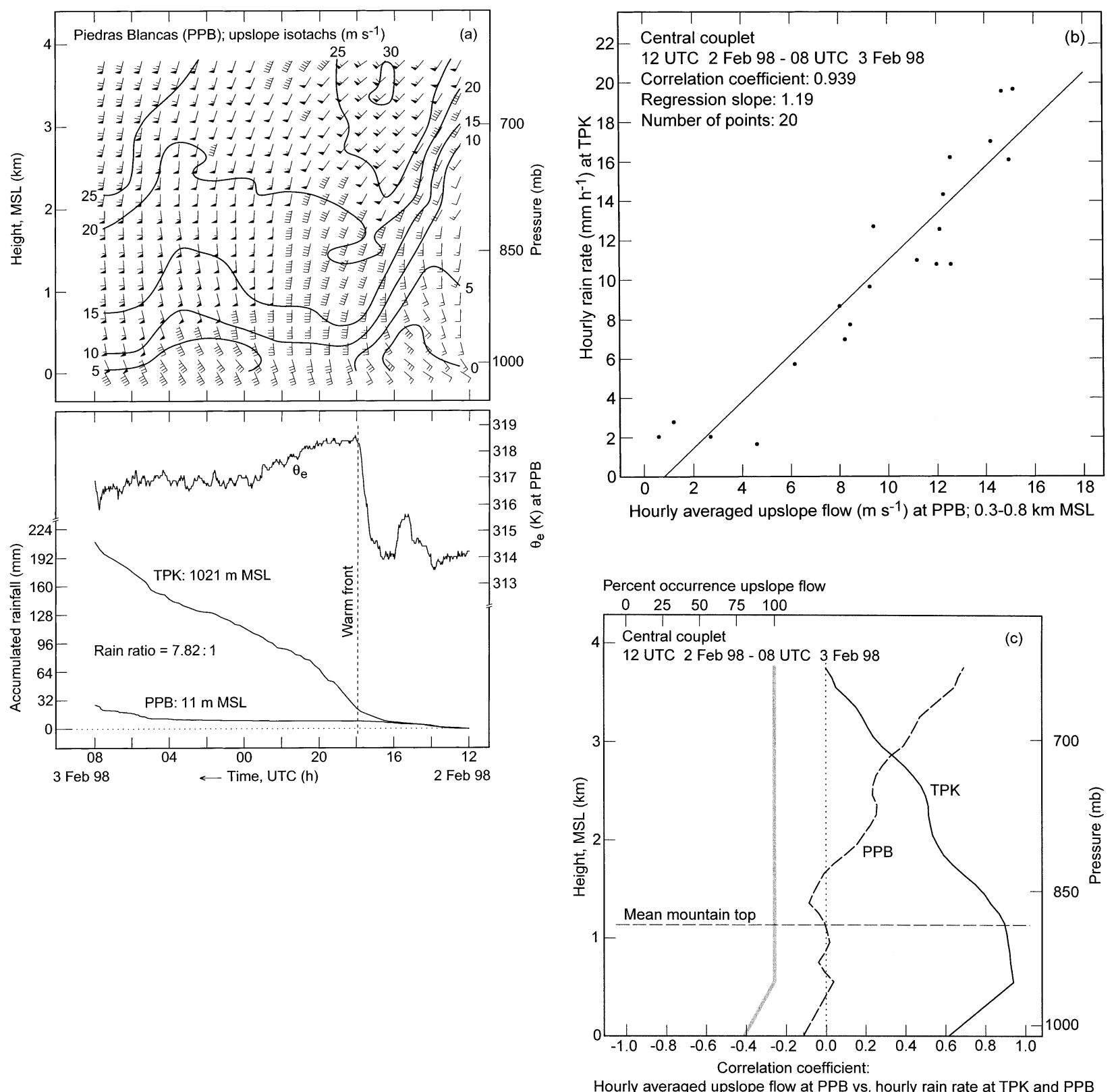

FIG. 4. (a) Time-height section of hourly averaged horizontal wind profiles and upslope-component isotachs at PPB (top panel), and time series traces of surface $\theta_{e}$ at PPB and accumulated rainfall at PPB and TPK (bottom panel), between 1200 UTC 2 Feb and 0800 UTC 3 Feb 1998. Wind flags and barbs are as in Fig. 3. (b) Scatterplot of hourly averaged layer-mean (0.3-0.8 km MSL) upslope flow at PPB vs hourly rain rate at TPK for the period shown in (a). The linear regression fit is shown. (c) Vertical profiles of linear correlation coef (black) based on hourly averaged profiles of upslope flow at PPB vs hourly rain rate at TPK (solid) and PPB (dashed) for the period shown in (a). The vertical profile of percent occurrence of upslope flow is also shown (gray shade), as is the mean mountaintop height of the neighboring coastal mountains.

rain rate at TPK (Fig. 4c, solid line) shows a large correlation below mountaintop, then a sharp decrease with height aloft. Because this case represents an extreme example of orographic rainfall variation between the mountains and the coast, we also calculated the correlation profile for upslope flow versus rain rate at PPB (Fig. 4c, dashed line). Not surprisingly, the magnitude of the low-level upslope flow at PPB was not correlated well with the rain rate at this site (i.e., the terrain did not affect rainfall at PPB, only in the downstream coastal mountains).

Profiler observations from the southern couplet at GLA on 23 February (Fig. 5a) mirrored those from farther north, that is, the strongest low-level upslope flow 

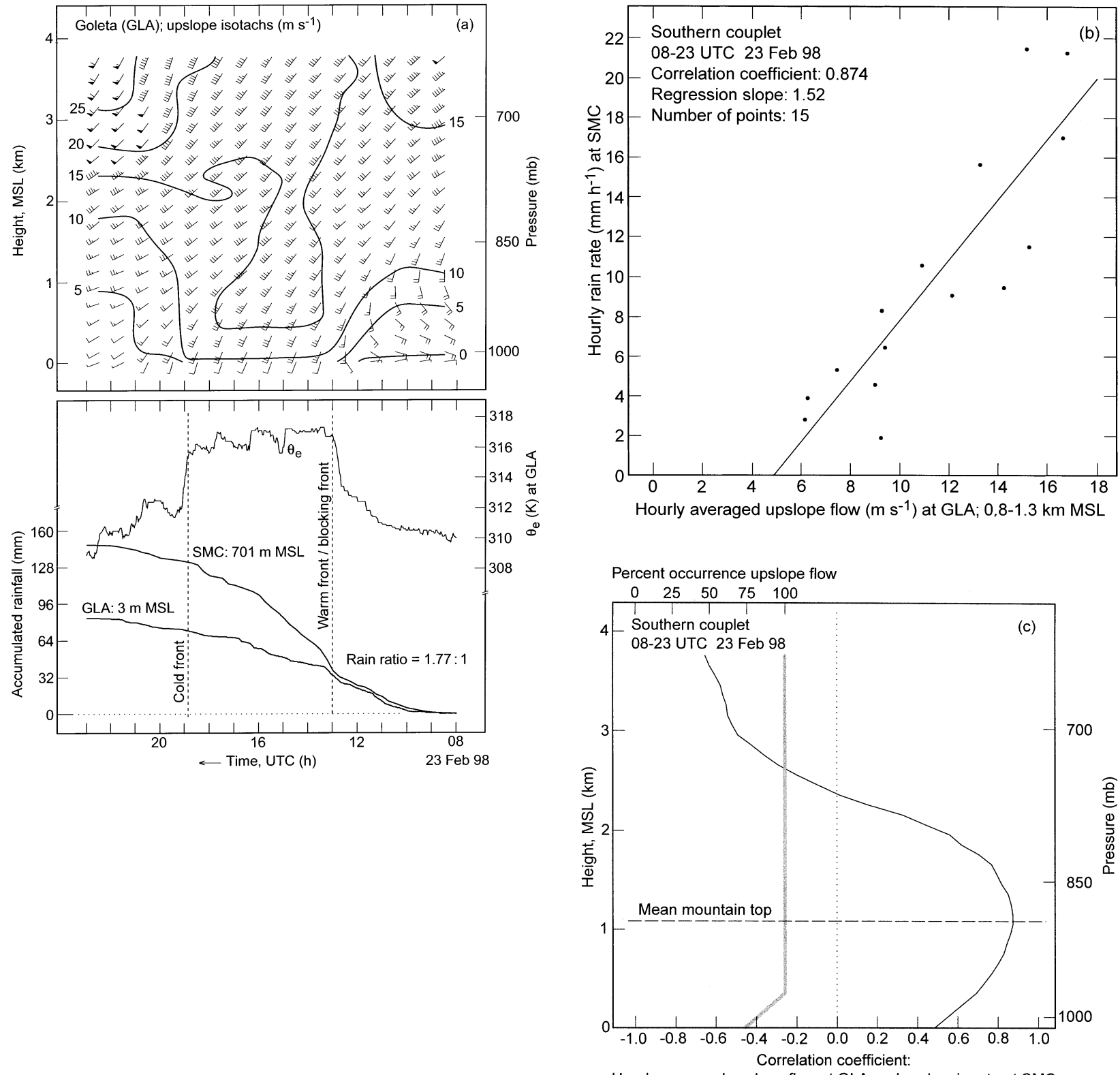

Hourly averaged upslope flow at GLA vs. hourly rain rate at SMC

FIG. 5. (a) Time-height section of hourly averaged horizontal wind profiles and upslope-component isotachs at GLA (top panel), and time series traces of surface $\theta_{e}$ at GLA and accumulated rainfall at GLA and SMC (bottom panel), between 0800 UTC and 2300 UTC 23 Feb 1998. Wind flags and barbs are as in Fig. 3. (b) Scatterplot of hourly averaged layer-mean (0.8-1.3 km MSL) upslope flow at GLA vs hourly rain rate at SMC for the period shown in (a). The linear regression fit is shown. (c) Vertical profile of linear correlation coef (black) based on hourly averaged profiles of upslope flow at GLA vs hourly rain rate at SMC for the period shown in (a). The vertical profile of percent occurrence of upslope flow is also shown (gray shade), as is the mean mountaintop height of the neighboring coastal mountains.

was observed in the high- $\theta_{e}$ warm sector. Though the rainfall ratio between the mountain and coastal sites was less than that observed at the other couplets, this value still represents a larger-than-average ratio for this couplet (Table 2). The scatterplot of upslope flow at GLA versus rain rate at SMC for the layer of maximum correlation (Fig. 5b) yields a correlation coefficient of 0.874 and a regression slope of 1.52 . This slope is the largest of the three couplets, as is the terrain steepness. The vertical structure of the correlation profile at the southern couplet (Fig. 5c), and the magnitude of the correlation values at low levels, are comparable to what was obtained at the northern two couplets.

For each unblocked event, we estimated the efficiency of hydrometeor generation associated with orographic lift. This was accomplished by dividing the mean rain rate observed at each mountain site by the mean rain rate calculated from Eq. (2) using the mean barrier 
steepness at each couplet (Table 1) and representative thermodynamic and kinematic observations for that event. This exercise was carried out only for the unblocked warm-sector cases where orographic lift was the dominant forcing mechanism for generating rainfall in the coastal mountains. Thermodynamic data at the northern couplet were obtained from the surface mountain site at CZD. At the central couplet, thermodynamic data were acquired from NOAA's P-3 research aircraft and from rawinsonde soundings at Vandenberg and Oakland, California. A Vandenberg sounding was used for the case at the southern couplet. At each couplet, a timeaveraged, layer-mean value of upslope flow below mean mountaintop height was determined from the coastal wind-profiler and surface data. The rain-rate efficiency differed only slightly from couplet to couplet, ranging from $17.2 \%$ at the southern couplet to $19.0 \%$ at the northern couplet, thus suggesting that microphysical processes were similar above the different coastal mountain ranges and that the statistical results from these couplets can be intercompared. These values mirror the 17.4\% efficiency obtained in Elliot and Hovind (1964) for stably stratified flow impacting the Santa Ynez coastal mountains in the vicinity of the southern couplet, thus providing further evidence of the common character of the microphysics above the coastal mountains. Given that the maximum correlation of upslope flow versus rain rate was very large for each case, it is likely that the microphysics at each couplet also did not change appreciably during the course of each event.

\section{b. Blocked cases}

Mountains can have a profound impact on the lower troposphere via "upstream blocking," including the deflection of low-level flow upstream, and below the top, of mountain ranges (e.g., Bell and Bosart 1988; Colle and Mass 1995). Blocking commonly results in the formation of a barrier jet below mountaintop that parallels the long axis of quasi-two-dimensional high terrain (e.g., Parish 1982; Overland and Bond 1995; Doyle 1997) such as California's coastal mountain ranges. Another manifestation of blocked flow is a layer of enhanced static stability that caps the barrier jet and slopes downward to the surface immediately upstream of the mountains (e.g., Overland and Bond 1995; Doyle 1997), resulting in a terrain-induced baroclinic zone in California's coastal zone. The sloping isentropes within this zone represent a secondary orographic forcing mechanism for precipitation, thus producing rainfall enhancement upstream of the coastal orography (Doyle 1997). A similar upwind redistribution of precipitation by blocked flows has occurred in association with many mountain ranges worldwide (e.g., Grossman and Durran 1984; Dunn 1987; Peterson et al. 1991; Sinclair et al. 1997).

This subsection presents a case-study correlation analysis from each of the three couplets for blocked flow conditions (Table 2). Unlike the unblocked warmsector cases, the blocked cases contained shallow flow that was oriented roughly parallel to the mountain barrier for the duration of the event, with weak downslopecomponent flow commonly observed at the lowest levels (Figs. 6a-8a). In addition, each blocked case possessed barrier-jet characteristics near or below mountaintop (terrain-parallel isotachs not shown). At each of the three couplets the mountain-to-coast rainfall ratio for the blocked cases was considerably smaller than that for the unblocked cases and for the CALJET winter season (Table 2) - comparisons that support the assertion that isentropic lift over a shallow blocked air stream resulted in significant rain at the coast. Surface traces of $\theta_{e}$ are not shown, because the surface conditions were decoupled from transient features above the shallow blocked flow.

The correlation profile at each couplet for blocked conditions (solid curves in Figs. 6b-8b) has its largest value just above mountaintop and then decreases with height above this maximum, similar to what occurred in the unblocked events (dashed curves in Figs. 6b, 7b, and $8 b$ ). Peak correlation coefficients for the blocked and unblocked events range over $0.761-0.832$ and $0.874-0.939$, respectively. The smaller peak values, together with the smaller rainfall ratios, for the blocked cases suggest that the shallow blocked air masses reduced the impact of mountaintop upslope flow on rainfall in the coastal mountains. Below mountaintop, the correlation values for blocked conditions generally decreases with decreasing height, because the lowest levels contained mostly terrain-parallel or weakly downslopecomponent flow. In stark contrast, the unblocked events maintain high correlations below mountaintop, because the upslope flow in these events extended downward toward the surface.

\section{c. A case of complex flow at the northern couplet}

To investigate the statistical relationship between upslope flow and rain rate on a case-by-case basis across a broad spectrum of events, we also applied the correlation analysis technique to data from the northern couplet on 5-6 February 1998. This lengthy case was characterized by a complex series of frontal passages and alternating periods of shallow blocked and unblocked flow (Fig. 9a). Because this case exhibited a variety of low-level flow regimes that commonly impact the northern couplet, it is not surprising that the mountain-to-coast rainfall ratio for this event (i.e., 2.16:1; Fig. 9a) mirrored that for the CALJET winter season (Table 2). The correlation coefficient profile for this case (Fig. 9b) contains a maximum value of 0.877 at $0.85 \mathrm{~km}$ MSL or slightly above mountaintop, similar to the magnitude and altitude of the correlation maxima diagnosed during the unblocked and blocked cases at the northern couplet. The correlation coefficient for this event is small at the surface, where only a small fraction of hourly surface 

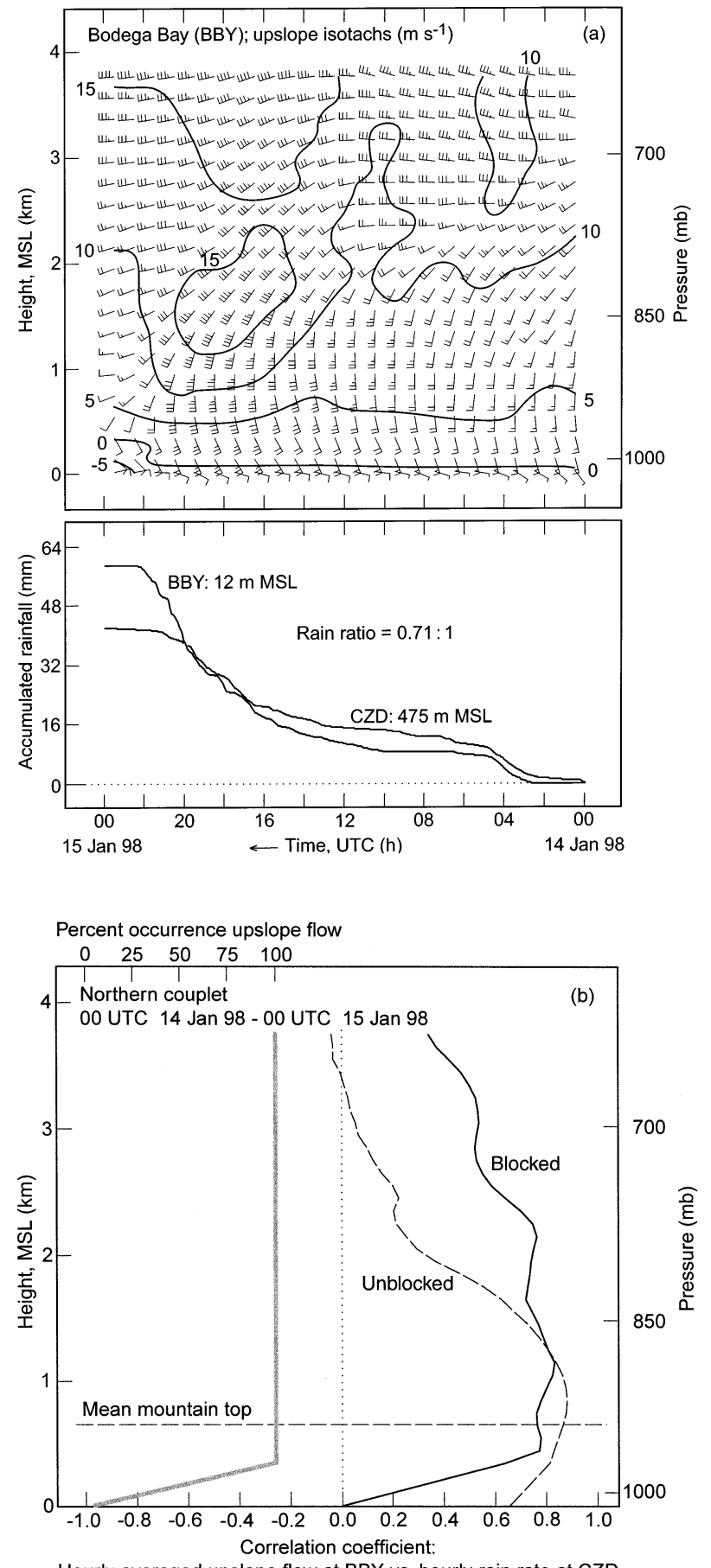

Hourly averaged upslope flow at BBY vs. hourly rain rate at CZD

FIG. 6. (a) Time-height section of hourly averaged horizontal wind profiles and upslope-component isotachs at BBY (top panel), and time series traces of accumulated rainfall at BBY and CZD (bottom panel), between 0000 UTC 14 Jan and 0000 UTC 15 Jan 1998. Wind flags and barbs are as in Fig. 3. (b) Vertical profile of linear correlation coef (solid black) based on hourly averaged profiles of upslope flow at BBY vs hourly rain rate at CZD for the period shown in (a). The vertical profile of percent occurrence of upslope flow is also shown (gray shade), as is the correlation coef profile from Fig. 3c (dashed) and the mean mountaintop height of the neighboring coastal mountains.
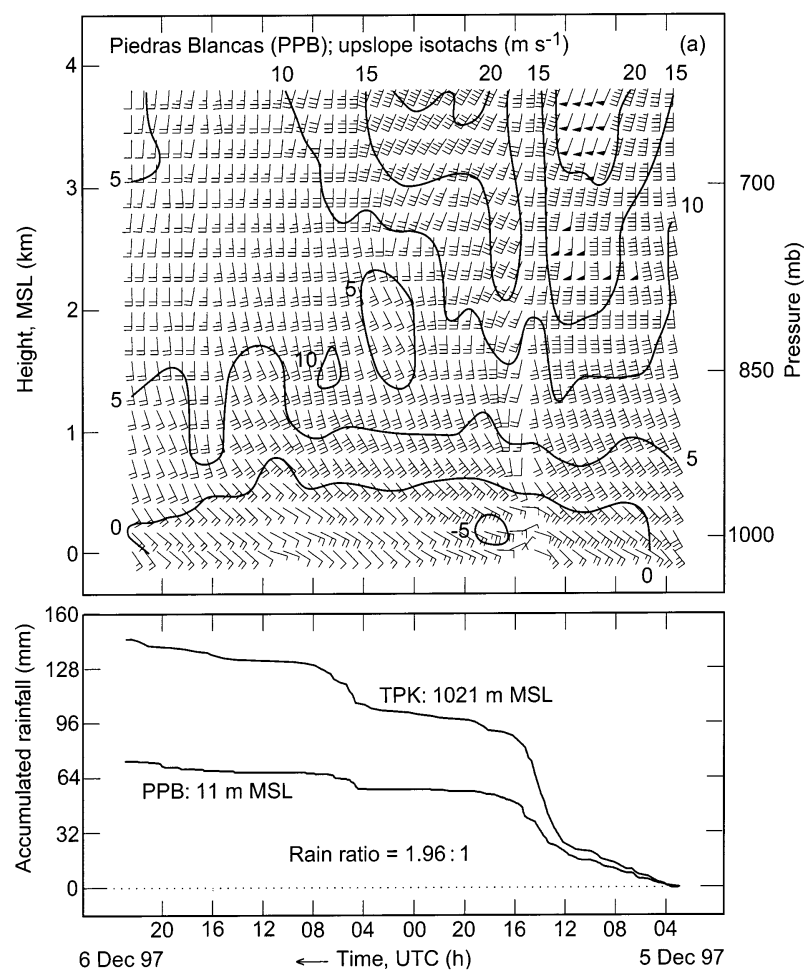

Percent occurrence upslope flow

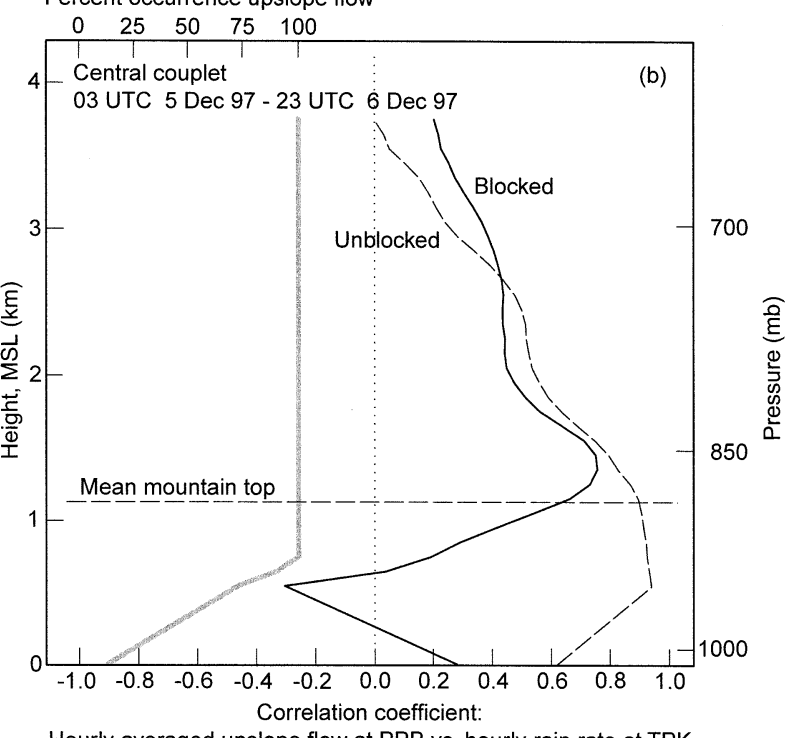

Hourly averaged upslope flow at PPB vs. hourly rain rate at TPK

FIG. 7. (a) Time-height section of hourly averaged horizontal wind profiles and upslope-component isotachs at PPB (top panel), and time series traces of accumulated rainfall at PPB and TPK (bottom), between 0300 UTC 5 Dec and 2300 UTC 6 Dec 1997. Wind flags and barbs are as in Fig. 3. (b) Vertical profile of linear correlation coef (solid black) based on hourly averaged profiles of upslope flow at PPB vs hourly rain rate at TPK for the period shown in (a). The vertical profile of percent occurrence of upslope flow is also shown (gray shade), as is the correlation coef profile from Fig. 4c (dashed) and the mean mountaintop height of the neighboring coastal mountains. 

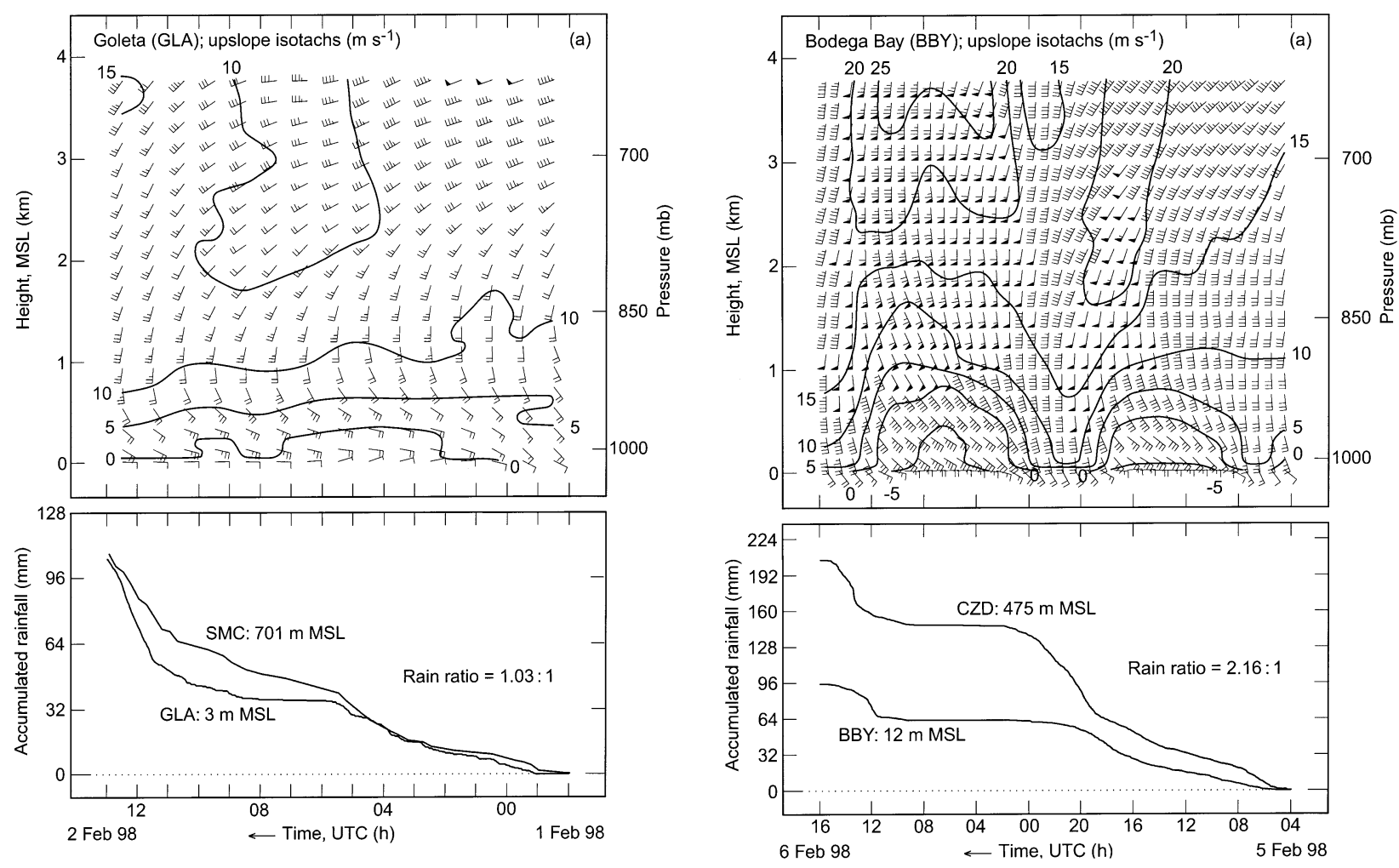

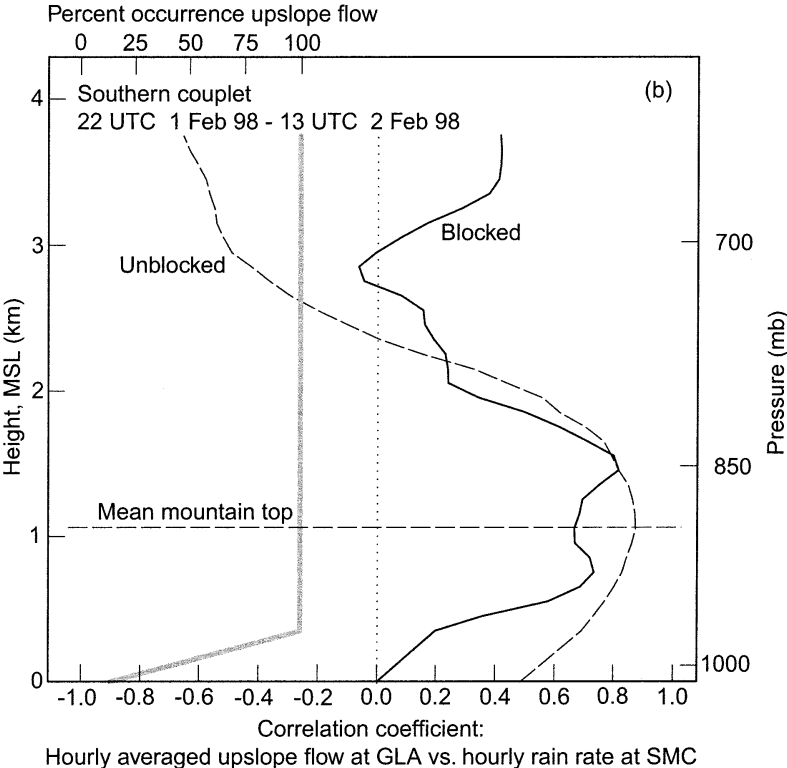

FIG. 8. (a) Time-height section of hourly averaged horizontal wind profiles and upslope-component isotachs at GLA (top panel), and time series traces of accumulated rainfall at GLA and SMC (bottom panel), between 2200 UTC 1 Feb and 1300 UTC 2 Feb 1998. Wind flags and barbs are as in Fig. 3. (b) Vertical profile of linear correlation coef (solid black) based on hourly averaged profiles of upslope flow at GLA vs hourly rain rate at SMC for the period shown in (a). The vertical profile of percent occurrence of upslope flow is also shown (gray shade), as is the correlation coef profile from Fig. 5c (dashed) and the mean mountaintop height of the neighboring coastal mountains.

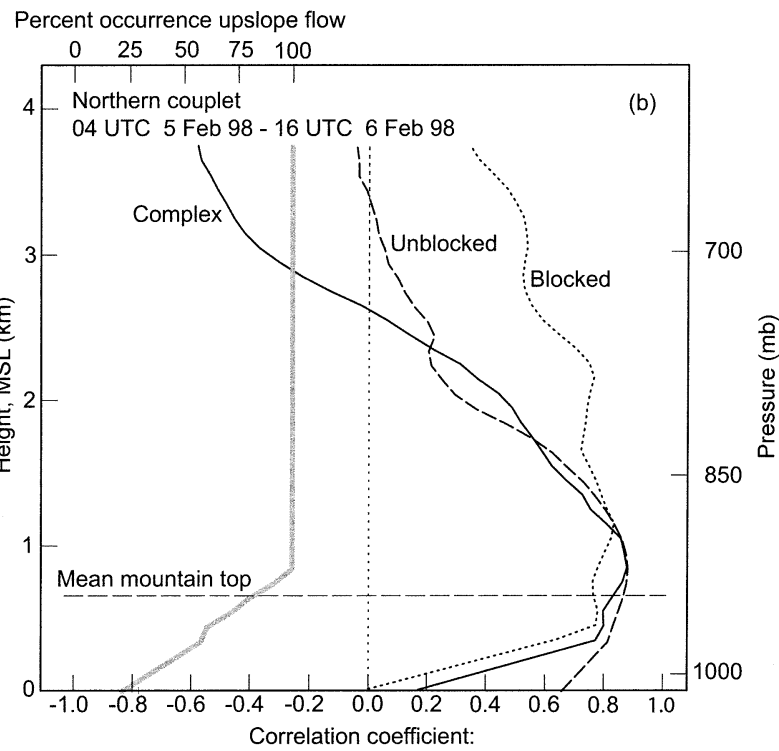

Hourly averaged upslope flow at BBY vs. hourly rain rate at $C Z D$

FIG. 9. (a) Time-height section of hourly averaged horizontal wind profiles and upslope-component isotachs at BBY (top panel), and time series traces of accumulated rainfall at BBY and CZD (bottom panel), between 0400 UTC 5 Feb and 1600 UTC 6 Feb 1998. Wind flags and barbs are as in Fig. 3. (b) Vertical profile of linear correlation coefficient (solid black) based on hourly averaged profiles of upslope flow at BBY vs hourly rain rate at CZD for the period shown in (a). The vertical profile of percent occurrence of upslope flow is also shown (gray shade), as are the correlation coef profiles from Fig. 6b (dashed) and Fig. 3c (dotted). The mean mountaintop height of the neighboring coastal mountains is also shown. 
TABLE 3. Northern couplet case inventory for the statistical analysis of upslope flow at BBY vs rain rate at CZD for the CALJET winter season.*

\begin{tabular}{|c|c|c|c|c|c|c|c|}
\hline Case & Event (1997/98) & $\begin{array}{l}\text { Duration } \\
\text { (h) }\end{array}$ & $\begin{array}{c}\mathrm{CZD} \\
\text { rainfall } \\
(\mathrm{mm})\end{array}$ & $\begin{array}{c}\text { CZD } \\
\text { rain rate } \\
\left(\mathrm{mm} \mathrm{h}^{-1}\right)\end{array}$ & $\begin{array}{l}\text { BBY } \\
\text { rainfall } \\
(\mathrm{mm})\end{array}$ & $\begin{array}{c}\mathrm{BBY} \\
\text { rain rate } \\
\left(\mathrm{mm} \mathrm{h}^{-1}\right)\end{array}$ & $\begin{array}{c}\text { Rainfall } \\
\text { ratio } \\
\text { (CZD/BBY) }\end{array}$ \\
\hline 1 & 1000 UTC 24 Nov-2300 UTC 24 Nov & 13 & 40.46 & 3.11 & 8.07 & 0.62 & 5.01 \\
\hline 2 & 0200 UTC 26 Nov-0000 UTC 27 Nov & 22 & 80.64 & 3.67 & 37.35 & 1.70 & 2.16 \\
\hline 3 & 1900 UTC 29 Nov-0600 UTC 30 Nov & 11 & 25.61 & 2.33 & 22.94 & 2.09 & 1.12 \\
\hline 4 & 1900 UTC 3 Dec-1000 UTC 4 Dec & 15 & 16.00 & 1.07 & 12.25 & 0.82 & 1.31 \\
\hline 5 & 0000 UTC 5 Dec-1000 UTC 5 Dec & 10 & 21.60 & 2.16 & 6.75 & 0.68 & 3.20 \\
\hline 6 & 0700 UTC 7 Dec-2000 UTC 7 Dec & 13 & 40.62 & 3.12 & 16.34 & 1.26 & 2.49 \\
\hline 7 & 0400 UTC 14 Dec-2000 UTC 14 Dec & 16 & 52.35 & 3.27 & 40.60 & 2.54 & 1.29 \\
\hline 8 & 0000 UTC 2 Jan-0300 UTC 3 Jan & 27 & 79.67 & 2.95 & 18.55 & 0.69 & 4.29 \\
\hline 9 & 1200 UTC 3 Jan-0800 UTC 4 Jan & 20 & 65.84 & 3.29 & 13.56 & 0.68 & 4.86 \\
\hline 10 & 2200 UTC 9 Jan-2000 UTC 10 Jan & 22 & 29.28 & 1.33 & 17.27 & 0.79 & 1.70 \\
\hline 11 & 0600 UTC 11 Jan-0000 UTC 13 Jan & 42 & 203.45 & 4.84 & 36.30 & 0.86 & 5.60 \\
\hline 12 & 0000 UTC 14 Jan-0000 UTC 15 Jan & 24 & 42.03 & 1.75 & 58.81 & 2.45 & 0.71 \\
\hline 13 & 0000 UTC 15 Jan-0000 UTC 16 Jan & 24 & 30.50 & 1.27 & 15.50 & 0.65 & 1.97 \\
\hline 14 & 0300 UTC 19 Jan-2200 UTC 19 Jan & 19 & 19.60 & 1.03 & 7.02 & 0.37 & 2.79 \\
\hline 15 & 1900 UTC 23 Jan-0700 UTC 24 Jan & 12 & 20.32 & 1.69 & 5.50 & 0.46 & 3.69 \\
\hline 16 & 0000 UTC 26 Jan-0400 UTC 27 Jan & 28 & 88.43 & 3.16 & 22.26 & 0.80 & 3.97 \\
\hline 17 & 0000 UTC 29 Feb-1100 UTC 29 Jan & 11 & 50.25 & 4.57 & 17.88 & 1.63 & 2.81 \\
\hline 18 & 0400 UTC 5 Feb-1600 UTC 6 Feb & 36 & 204.83 & 5.69 & 94.69 & 2.63 & 2.16 \\
\hline 19 & 0500 UTC 7 Feb-1800 UTC 7 Feb & 13 & 50.11 & 3.85 & 18.31 & 1.41 & 2.74 \\
\hline 20 & 1300 UTC $10 \mathrm{Feb}-2200$ UTC $10 \mathrm{Feb}$ & 9 & 25.76 & 2.86 & 26.70 & 2.97 & 0.96 \\
\hline 21 & 1000 UTC 12 Feb-2300 UTC 12 Feb & 13 & 20.03 & 1.54 & 19.00 & 1.46 & 1.05 \\
\hline 22 & 1100 UTC 16 Feb-0000 UTC 17 Feb & 13 & 39.41 & 3.03 & 17.52 & 1.35 & 2.25 \\
\hline 23 & 0000 UTC 19 Feb-2300 UTC 19 Feb & 23 & 114.92 & 5.00 & 74.28 & 3.23 & 1.55 \\
\hline 24 & 0900 UTC 23 Feb-2100 UTC 23 Feb & 12 & 34.03 & 2.84 & 21.53 & 1.79 & 1.58 \\
\hline 25 & 1300 UTC 12 Mar-0900 UTC 13 Mar & 20 & 39.41 & 1.97 & 24.36 & 1.22 & 1.62 \\
\hline Totals & & 468 & 1435.15 & & 653.34 & & \\
\hline \multicolumn{3}{|l|}{ Avg } & & 3.07 & & 1.40 & 2.20 \\
\hline \multicolumn{3}{|c|}{ Percent of total rainfall during CALJET winter season } & 0.67 & & 0.67 & & \\
\hline \multicolumn{3}{|c|}{ Total rainfall during CALJET winter season } & 2157.55 & & 972.23 & & 2.22 \\
\hline
\end{tabular}

* The winter season at this couplet is defined as 20 Nov 1997-31 Mar 1998. Events of less than 12.5 mm total rainfall and less than 8-h duration at the mountain site were excluded from the inventory.

winds contained an upslope component. A mesoscale and microphysical description of this event is found in Ralph et al. (1998) and White et al. (1999). Comparable events of extended duration did not occur at the two other couplets.

\section{Winter-season statistical assessment}

Case studies highlight characteristics unique to those cases, but they are not necessarily representative of mean behaviors over extended periods of time. Therefore, to extend the statistical significance of the casestudy results, we examined the linear relationship between upslope flow and rain rate at each observing couplet for the entire CALJET winter season. CALJET serendipitously coincided with a strong El Niño episode that may have contributed to the record rainfall and numerous rain events observed across much of coastal California (Livezey et al. 1997) during the winter of 1997/98. Hence, the fortuitous timing of CALJET proved ideal for generating these winter-season statistics. We examined the rainfall database from late November 1997 through March 1998 and chose events at each mountain site that we deemed significant, that is, at least $12.5 \mathrm{~mm}$ rainfall and $8 \mathrm{~h}$ duration. These min- imum criteria were chosen to increase the likelihood that rain events yielded significant total rainfall attributable to orographic ascent. For the northern couplet, a total of 25 cases spanning $468 \mathrm{~h}$ fit these criteria (Table 3 ). This 25 -case inventory was representative of rainfall behavior at the northern couplet for the entire winter season because two-thirds of the rainfall for the entire season was captured at BBY and CZD during this inventory, and because the rain ratio between $C Z D$ and BBY for this inventory $(2.20: 1)$ was nearly identical to that for the entire winter season $(2.22: 1)$. For the central couplet, 20 cases representing $362 \mathrm{~h}$ of data were compiled (Table 4). The inventory for the southern couplet comprised 9 events spanning $145 \mathrm{~h}$ (Table 5). As at the northern couplet, these inventories were representative of rainfall behavior for the winter season. When a coastal profiler was inoperative during a rain event that met the criteria outlined above, the event was not included in a winter-season inventory. These inventories contain data from landfalling storms with widely differing synoptic characteristics, from openwave warm-sectors to deeply occluded frontal passages.

A winter-season profile of linear correlation coefficient was calculated for each couplet. To generate each profile, all of the hourly rain-rate observations and cor- 
TABLE 4. Central couplet case inventory for the statistical analysis of upslope flow at PPB vs rain rate at TPK for the CALJET winter season.*

\begin{tabular}{|c|c|c|c|c|c|c|c|}
\hline Case & Event $(1997 / 98)$ & $\begin{array}{l}\text { Duration } \\
\text { (h) }\end{array}$ & $\begin{array}{l}\text { TPK } \\
\text { rainfall } \\
(\mathrm{mm})\end{array}$ & $\begin{array}{c}\text { TPK } \\
\text { rain rate } \\
\left(\mathrm{mm} \mathrm{h}^{-1}\right)\end{array}$ & $\begin{array}{c}\text { PPB } \\
\text { rainfall } \\
(\mathrm{mm})\end{array}$ & $\begin{array}{c}\text { PPB } \\
\text { rain rate } \\
\left(\mathrm{mm} \mathrm{h}^{-1}\right)\end{array}$ & $\begin{array}{c}\text { Rainfall } \\
\text { ratio } \\
\text { (TPK/PPB) }\end{array}$ \\
\hline 1 & 0300 UTC 5 Dec-2300 UTC 6 Dec & 44 & 144.56 & 3.29 & 73.60 & 1.67 & 1.96 \\
\hline 2 & 1200 UTC 7 Dec-2300 UTC 7 Dec & 11 & 48.51 & 4.41 & - & - & - \\
\hline 3 & 1200 UTC 14 Dec-2000 UTC 14 Dec & 8 & 69.09 & 8.64 & 17.00 & 2.13 & 4.06 \\
\hline 4 & 1400 UTC 2 Jan-1900 UTC 3 Jan & 29 & 60.71 & 2.09 & 16.85 & 0.58 & 3.60 \\
\hline 5 & 0600 UTC 4 Jan-2000 UTC 4 Jan & 14 & 32.77 & 2.34 & 10.31 & 0.74 & 3.18 \\
\hline 6 & 0900 UTC 9 Jan-1100 UTC 10 Jan & 26 & 87.38 & 3.36 & 22.33 & 0.86 & 3.91 \\
\hline 7 & 0800 UTC 12 Jan-0100 UTC 13 Jan & 17 & 68.07 & 4.00 & 8.52 & 0.50 & 7.99 \\
\hline 8 & 2300 UTC 14 Jan-0500 UTC 16 Jan & 30 & 128.02 & 4.27 & 22.79 & 0.76 & 5.62 \\
\hline 9 & 2100 UTC 18 Jan-1000 UTC 19 Jan & 13 & 75.69 & 5.82 & 14.33 & 1.10 & 5.28 \\
\hline 10 & 0300 UTC 29 Jan-1800 UTC 29 Jan & 15 & 95.00 & 6.33 & 11.78 & 0.79 & 8.06 \\
\hline 11 & 1000 UTC 31 Jan-2100 UTC 31 Jan & 11 & 47.75 & 4.34 & 23.04 & 2.09 & 2.07 \\
\hline 12 & 1600 UTC 1 Feb-0300 UTC 2 Feb & 11 & 137.67 & 12.52 & 37.85 & 3.44 & 3.64 \\
\hline 13 & 0800 UTC 2 Feb-1700 UTC 3 Feb & 33 & 343.66 & 10.41 & 83.60 & 2.53 & 4.11 \\
\hline 14 & 1000 UTC 14 Feb-0200 UTC 15 Feb & 16 & 86.11 & 5.38 & 37.47 & 2.34 & 2.30 \\
\hline 15 & 1800 UTC 16 Feb-0400 UTC 17 Feb & 10 & 63.50 & 6.35 & 20.33 & 2.03 & 3.12 \\
\hline 16 & 1700 UTC 19 Feb-0100 UTC 20 Feb & 8 & 50.29 & 6.29 & 20.84 & 2.61 & 2.41 \\
\hline 17 & 1400 UTC 21 Feb-0400 UTC 22 Feb & 14 & 96.27 & 6.88 & 19.36 & 1.38 & 4.97 \\
\hline 18 & 1000 UTC 23 Feb-1900 UTC 23 Feb & 9 & 31.24 & 3.47 & 5.02 & 0.56 & 6.22 \\
\hline 19 & 1900 UTC 5 Mar-0800 UTC 6 Mar & 13 & 30.99 & 2.38 & 10.77 & 0.83 & 2.88 \\
\hline 20 & 0500 UTC $24 \mathrm{Mar}-1100$ UTC $25 \mathrm{Mar}$ & 30 & 100.08 & 3.34 & 31.42 & 1.05 & 3.19 \\
\hline \multicolumn{2}{|r|}{ 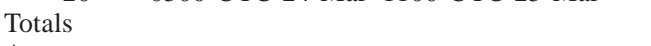 } & 362 & 1797.36 & & 487.21 & & \\
\hline \multicolumn{2}{|l|}{ Avg } & & & 4.97 & & 1.35 & 3.69 \\
\hline \multicolumn{2}{|c|}{ Percent of total rainfall during CALJET winter season } & & 0.80 & & 0.73 & & \\
\hline \multicolumn{2}{|c|}{ Total rainfall during CALJET winter season } & & 2256.79 & & 663.69 & & 3.40 \\
\hline
\end{tabular}

* The winter season at this couplet is defined as 1 Dec 1997-31 Mar 1998. Events of less than $12.5 \mathrm{~mm}$ total rainfall and less than 8-h duration at the mountain site were excluded from the inventory. Precipitation data were not available at PPB for case 2.

responding upslope-flow measurements (i.e., $U \geq 0 \mathrm{~m}$ $\mathrm{s}^{-1}$ ) from that couplet's winter-season inventory were first grouped together at each vertically averaged (i.e., 500-m thick) range gate and at the surface. Then, a correlation coefficient of upslope flow versus rain rate was derived for each range gate and at the surface, thus yielding a winter-season profile of correlation coefficient for that couplet. Because this statistical technique only used vertically averaged wind measurements that possessed an upslope component, a companion profile of the percent occurrence of upslope flow is also shown for each couplet.

The winter-season correlation coefficient profile at the northern couplet (Fig. 10) yields a maximum value of 0.644 at $0.95 \mathrm{~km}$ MSL, or $300 \mathrm{~m}$ above mean mountaintop. The correlation coefficient decreases significantly above and below the height of this maximum. The decrease in correlation below mountaintop, coupled

TABLE 5. Southern couplet case inventory for the statistical analysis of upslope flow at GLA vs rain rate at SMC for the CALJET winter season.*

\begin{tabular}{|c|c|c|c|c|c|c|c|}
\hline Case & Event (1997/98) & $\begin{array}{l}\text { Duration } \\
\text { (h) }\end{array}$ & $\begin{array}{l}\text { SMC } \\
\text { rainfall } \\
(\mathrm{mm})\end{array}$ & $\begin{array}{c}\text { SMC } \\
\text { rain rate } \\
\left(\mathrm{mm} \mathrm{h}^{-1}\right)\end{array}$ & $\begin{array}{l}\text { GLA } \\
\text { rainfall } \\
(\mathrm{mm})\end{array}$ & $\begin{array}{c}\text { GLA } \\
\text { rain rate } \\
\left(\mathrm{mm} \mathrm{h}^{-1}\right)\end{array}$ & $\begin{array}{c}\text { Rainfall } \\
\text { ratio } \\
\text { (SMC/GLA) }\end{array}$ \\
\hline 1 & 0800 UTC 5 Dec-1800 UTC 6 Dec & 34 & 199.14 & 5.86 & 178.13 & 5.24 & 1.12 \\
\hline 2 & 1400 UTC 9 Jan-1000 UTC 10 Jan & 20 & 78.99 & 3.95 & 76.02 & 3.80 & 1.04 \\
\hline 3 & 0600 UTC 29 Jan-1400 UTC 29 Jan & 8 & 57.15 & 7.14 & 28.87 & 3.61 & 1.98 \\
\hline 4 & 2200 UTC 1 Feb-1300 UTC 2 Feb & 15 & 108.20 & 7.21 & 105.48 & 7.03 & 1.03 \\
\hline 5 & 2300 UTC 2 Feb-1900 UTC 3 Feb & 20 & 137.47 & 6.87 & 86.67 & 4.33 & 1.59 \\
\hline 6 & 0000 UTC 17 Feb-1200 UTC 17 Feb & 12 & 35.56 & 2.96 & 32.17 & 2.68 & 1.11 \\
\hline 7 & 0200 UTC 22 Feb-1100 UTC 22 Feb & 9 & 47.24 & 5.25 & 58.52 & 6.50 & 0.81 \\
\hline 8 & 0800 UTC 23 Feb-2300 UTC 23 Feb & 15 & 147.32 & 9.82 & 83.32 & 5.55 & 1.77 \\
\hline 9 & 0000 UTC 6 Mar-1200 UTC 6 Mar & 12 & 16.00 & 1.33 & 13.41 & 1.12 & 1.19 \\
\hline \multicolumn{2}{|r|}{ (2) } & 145 & 827.07 & & 662.59 & & \\
\hline \multirow{2}{*}{\multicolumn{2}{|c|}{$\begin{array}{l}\text { Avg } \\
\text { Percent of total rainfall during CALJET winter season }\end{array}$}} & & & 5.70 & & 4.57 & 1.25 \\
\hline & & & 0.58 & & 0.53 & & \\
\hline \multicolumn{2}{|c|}{ Total rainfall during CALJET winter season } & & 1434.34 & & 1238.94 & & 1.16 \\
\hline
\end{tabular}

* The winter season at this couplet is defined as 1 Dec 1997-31 Mar 1998. Events of less than 12.5-mm total rainfall and less than 8-h duration at the mountain site were excluded from the inventory. 
Percent occurrence upslope flow

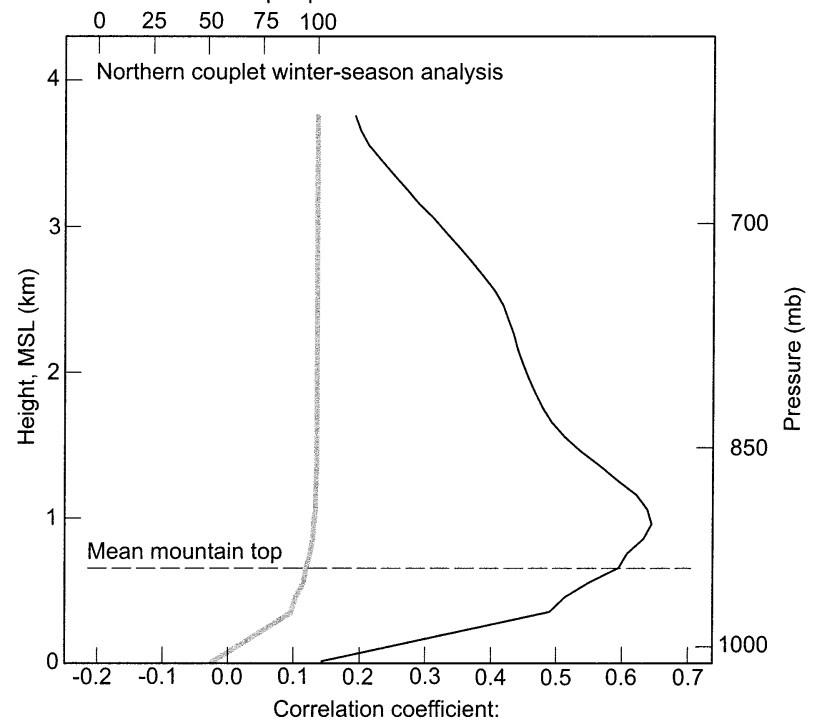

Hourly averaged upslope flow at BBY vs. hourly rain rate at CZD

FIG. 10. Vertical profiles of linear correlation coef (black) based on hourly averaged profiles of upslope flow at BBY vs hourly rain rate at CZD from the 25-case winter-season inventory. The vertical profile of percent occurrence of upslope flow is also shown (gray shade), as is the mean mountaintop height of the neighboring coastal mountains.

with the fact that the fractional occurrence of upslope flow decreased from $100 \%$ near mountain top to only $53 \%$ at the surface, are suggestive of BBY's susceptibility to a variety of shallow terrain-modulated flows forced by the locally complex orography (Ralph et al. 1999).

The winter-season correlation coefficient profile at the central couplet (Fig. 11) exhibits its largest values (i.e., $0.677-0.692$ ) in the layer between 0.55 and $1.45 \mathrm{~km}$ MSL. Above this broad maximum, the correlation coefficient decreases significantly with height similar to that observed at the northern couplet, though the initial significant decrease in correlation coefficient with height at the central couplet occurs at a higher altitude than at the northern couplet. This vertical offset is consistent with the difference in terrain height at the two couplets. Unlike at the northern couplet, however, the correlation at the central couplet remains relatively large below mountaintop. Furthermore, the surface winds at the central couplet possessed an upslope component $16 \%$ more often than at the northern couplet. These results suggest that the lower troposphere here was less susceptible to terrain-modulated flows than at the northern couplet, even though the terrain orientation at the two couplets was similar (Table 1).

The winter-season correlation coefficient profile at the southern couplet (Fig. 12) has a peak value of 0.560 at $0.85 \mathrm{~km}$ MSL, or $200 \mathrm{~m}$ below mean mountaintop. Above and below this peak, the correlation decreases steadily. Despite the disparity in mountain-barrier ori-

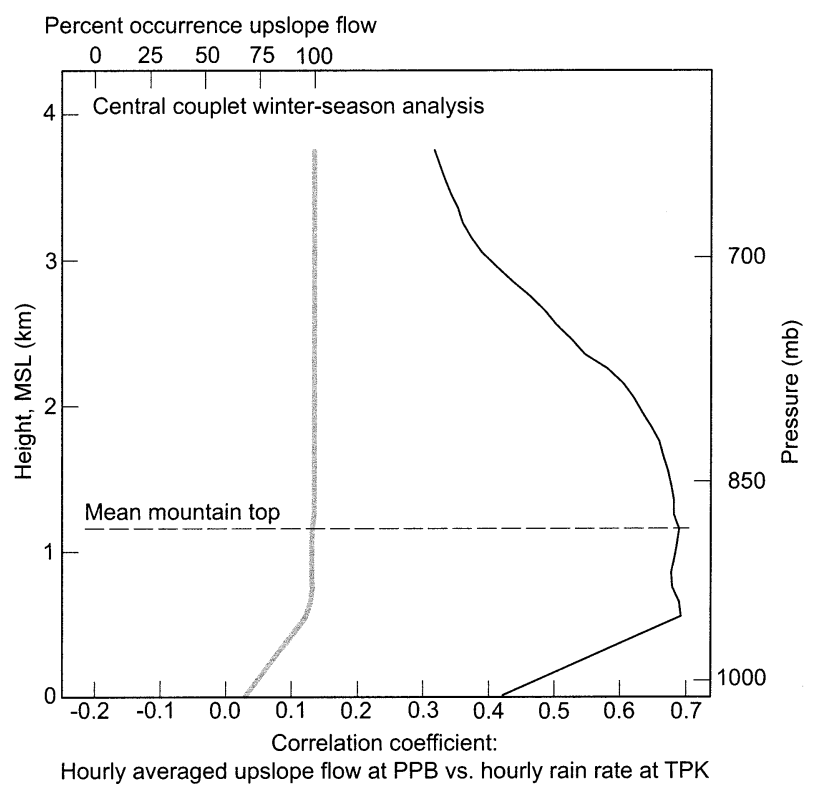

FIG. 11. Vertical profiles of linear correlation coef (black) based on hourly averaged profiles of upslope flow at PPB vs hourly rain rate at TPK from the 20-case winter-season inventory. The vertical profile of percent occurrence of upslope flow is also shown (gray shade), as is the mean mountaintop height of the neighboring coastal mountains.

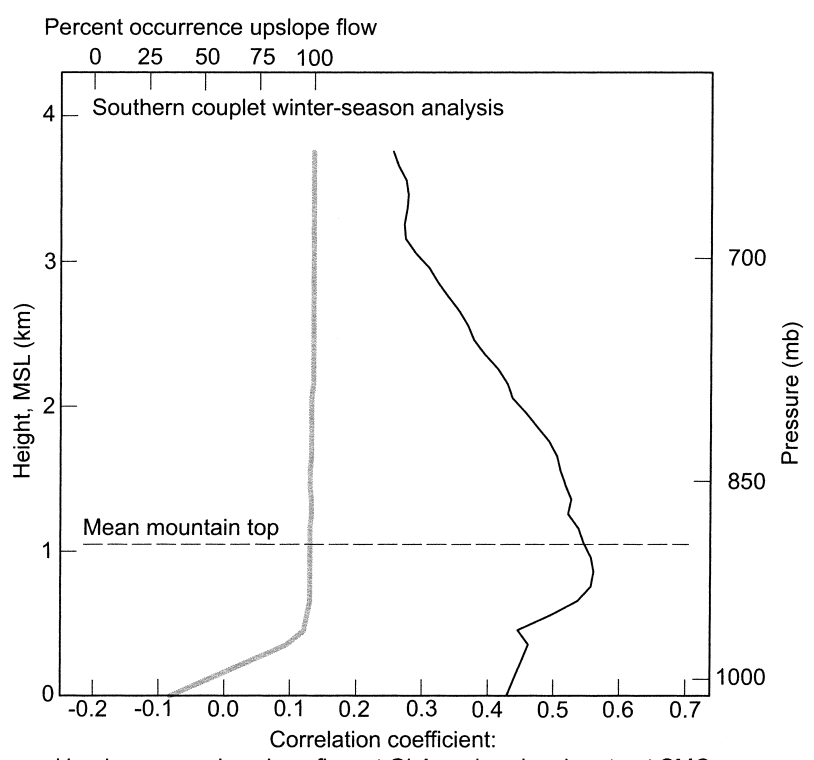

Hourly averaged upslope flow at GLA vs. hourly rain rate at SMC

FIG. 12. Vertical profiles of linear correlation coef (black) based on hourly averaged profiles of upslope flow at GLA vs hourly rain rate at SMC from the 9-case winter-season inventory. The vertical profile of percent occurrence of upslope flow is also shown (gray shade), as is the mean mountaintop height of the neighboring coastal mountains. 


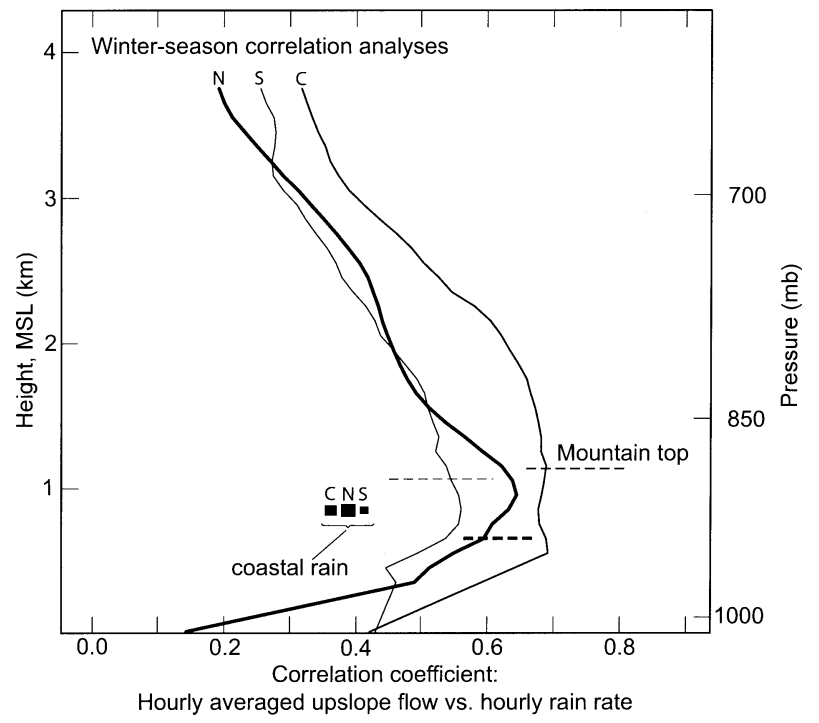

FIG. 13. Vertical profiles of winter-season linear correlation coef based on hourly averaged profiles of upslope flow at the coast vs hourly rain rate in the mountains for the northern couplet $(\mathrm{N}$ : bold solid), the central couplet (C: medium solid), and the southern couplet (S: thin solid). The mean mountaintop height of the neighboring coastal mountains for each couplet is also shown (relative line-weight convention same as for the correlation coef profiles). The solid squares correspond to the linear correlation coef based on hourly averaged upslope flow in the $0.6-1.1 \mathrm{~km}$ MSL layer at the coast vs hourly rain rate at the collocated wind-profiler sites at the northern, central, and southern couplets (large, medium, and small sizes, respectively).

entation between the southern couplet and the two other couplets (Table 1), the vertical structure of the correlation profile at the southern couplet is similar to its northern counterparts. However, given that upslope flow at the southern couplet's coastal site at GLA decreased from nearly $100 \%$ occurrence at mountaintop to only $35 \%$ at the surface (i.e., the smallest fractional occurrence of the three couplets), and based on a comparison of winter-season profiler data at GLA with companion profiler data at Santa Catalina and San Clemente Islands offshore of Los Angeles (not shown), the ambient southerly flow approaching the southern couplet was deflected by the terrain more frequently and more significantly than at the two other couplets. Despite the prevalence of blocking here, the surface upslope flow at the southern couplet is more positively correlated with mountain rain rate than at the other couplets where blocking was less pronounced. It is unclear precisely why the southern couplet exhibits the largest surface correlation coefficient, though it may be related to the west-east orientation of the barrier at this couplet versus the northwestsoutheast orientation of the barrier at the other couplets.

The winter-season correlation coefficient profiles from the three couplets are displayed together in Fig. 13. The maximum winter-season value at the northern, central, and southern couplets is a modest $0.644,0.692$, and 0.560 , respectively; that is, only $41 \%, 48 \%$, and
$31 \%$ of the variation in rain rate is accounted for by a linear relationship with the magnitude of the upslope flow at the height of maximum correlation. These modest values are not surprising, given that the winter-season composites include cases where orographic forcing was not the dominant mechanism for producing rainfall. Significantly, however, the winter-season correlation coefficient profiles demonstrate clearly that the rain in the coastal mountains was optimally tied to the magnitude of the upslope flow near mountaintop rather than at the surface or in the middle troposphere. These winter-season profiles also strongly resemble the case-study profiles presented earlier, with the exception that the peak correlation values in the case-study examples attribute as much as $88 \%$ of the rain-rate variation to linear changes in the magnitude of the upslope flow.

The winter-season correlation maximum is largest at the central couplet and smallest at the southern couplet, consistent with the winter-season rainfall characteristics observed at these couplets (Table 2). Specifically, the winter-season rainfall ratio between the mountain and coastal sites was largest at the central couplet and smallest at the southern couple; that is, the central and southern couplets experienced the greatest and least orographic rainfall enhancement in the mountains, respectively. The relative absence of low-level blocking at the central couplet likely contributed to the greatest orographic rain enhancement in the mountains and, hence, the largest peak correlation coefficient, because the lowlevel upslope flow directly ascended the mountain barrier. Conversely, the prevalence of low-level blocking at the southern couplet likely resulted in the smallest rainfall ratio and smallest peak correlation coefficient, because isentropic lift occurred over the blocked flow thus producing significant rain at the coast. Figure 13 also reveals that the correlation coefficients calculated from upslope flow $0.85 \mathrm{~km}$ above each coastal site and rain rate at the same coastal site are considerably less than the corresponding correlation coefficients based on upslope flow above each coastal site versus the rain rate at the downstream mountain site. In short, the low-level upslope flow observed above each coastal site is a much better indicator of rain intensity in the coastal mountains than at the coast.

\section{Impact of landfalling low-level jets on rain rate at the northern couplet}

A focal point of CALJET's observing strategy was to document the structure and physical processes in the low-level jet (LLJ) region ahead of landfalling cold fronts over the eastern Pacific Ocean, because it is believed that landfalling LLJs contribute to heavy orographic rainfall as they impact the windward slopes of coastal mountains (e.g., Browning et al. 1975). During CALJET, a prominent LLJ was observed by NOAA's P-3 research aircraft during 10 flights offshore of California. Composite profiles of wind velocity and mois- 


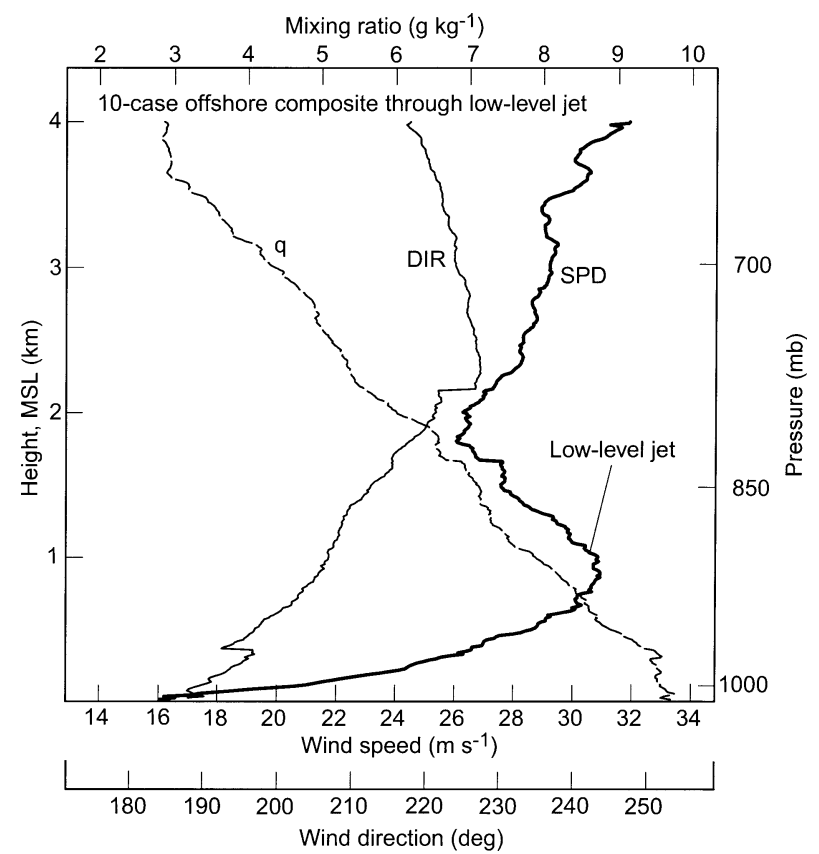

FIG. 14. Composite vertical profiles of wind speed (SPD, medium solid), wind direction (DIR, thin solid), and water vapor mixing ratio ( $q$, thin dashed) based on NOAA P-3 flight-level and dropsonde measurements taken over the eastern Pacific Ocean during 10 CALJET storms that contained an LLJ.

ture through the LLJ were generated (Fig. 14) using flight-level and dropsonde observations from those flights. To construct the composites, a representative pre-cold-frontal sounding through the LLJ from each case was interpolated onto a 10 -m-resolution vertical grid, and these gridded profiles were then averaged. The composite wind speed profile contains a LLJ of $\sim 31 \mathrm{~m}$ $\mathrm{s}^{-1}$ centered at about $0.9 \mathrm{~km}$ MSL and a local minimum of $\sim 26 \mathrm{~m} \mathrm{~s}^{-1}$ at about $1.8 \mathrm{~km}$ MSL. The companion wind-direction profile veers with height from southsouthwesterly near the ocean surface to southwesterly above the LLJ at $\sim 2 \mathrm{~km}$. The composite water vapor mixing ratio profile shows moist conditions (nearly 10 $\mathrm{g} \mathrm{kg}^{-1}$ ) below $\sim 300 \mathrm{~m} \mathrm{MSL}$, and a steady decrease of moisture with height aloft.

Despite the presence of well-defined LLJ characteristics over the open ocean, are LLJs readily observable at the coast or do they dissipate prior to landfall because of terrain blocking and enhanced friction in the coastal zone? If LLJs make landfall, do they modulate rainfall in California's coastal mountains? To answer these questions, we inspected the BBY profiler data from each of the 25 cases that composed the winter-season inventory at the northern couplet (Table 3) for evidence of a landfalling LLJ. We defined an LLJ as a maximum of total wind speed below $1.5 \mathrm{~km}$ MSL residing beneath a local minimum aloft. This low-level maximum was required to be at least $2 \mathrm{~m} \mathrm{~s}^{-1}$ larger than the minimum aloft. At least two consecutive hourly profiles meeting these criteria were required to generate a mean wind profile

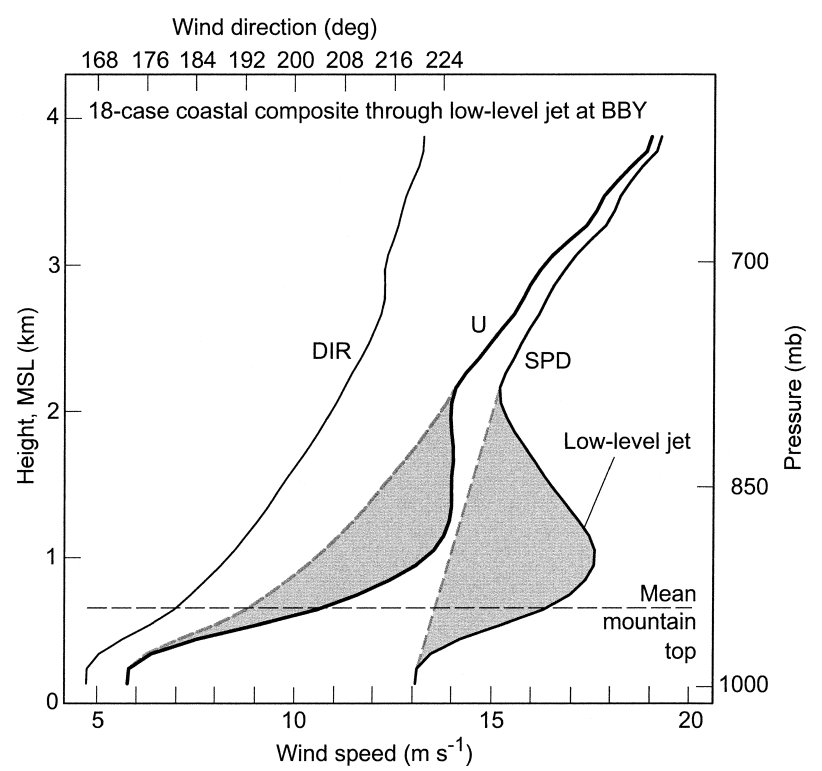

FIG. 15. Composite vertical profiles of wind speed (SPD, medium solid), wind direction (DIR, thin solid), and upslope flow ( $U$, bold solid) based on an averaged of the 18 CALJET winter-season cases from BBY that contained an LLJ. The gray-shaded dashed lines portray modified profiles of wind speed (medium) and upslope flow (bold) with the LLJ removed. The shaded regions portray the wind speed and upslope-flow perturbations associated with the LLJ. The mean mountaintop height of the neighboring coastal mountains is shown.

representative of an LLJ for that case. Based on these criteria, 18 of the 25 cases contained an LLJ episode (Table 6), totaling $81 \mathrm{~h}$ of data. Composite wind speed, wind direction, and upslope-flow profiles were constructed (Fig. 15) by averaging the mean wind profiles from the 18 LLJ events. The composite wind speed profile contains an LLJ of nearly $18 \mathrm{~m} \mathrm{~s}^{-1}$ at $\sim 1 \mathrm{~km}$ MSL, or only $\sim 100 \mathrm{~m}$ above that of the offshore composite (Fig. 14). However, the core speed within the coastal LLJ composite is $<60 \%$ of the magnitude of its offshore counterpart. Some of this difference may be due to the fact that the coastal and offshore composites were composed of different populations of LLJs, and that the P-3 flights from which the offshore composite was derived focused on the strongest events. It is also possible that at least part of this reduction in speed arose through enhanced frictional effects in the coastal zone. The composite wind-direction profile at BBY is rotated counterclockwise by $\sim 25^{\circ}$ below mean mountaintop relative to its offshore counterpart, thus suggesting that the coastal mountains may have deflected the low-level flow below jet level to a nearly terrainparallel orientation. The composite upslope-flow profile contains a local maximum of $\sim 14 \mathrm{~m} \mathrm{~s}^{-1}$ at about the height of the composite LLJ and above the shallow terrain-deflected flow. Similar LLJ composite structure was observed at the offshore profiler at FNI (location shown in Fig. 1) and in the downstream coastal mountain profiler at CZD (composites not shown). 
TABLE 6. Northern couplet case inventory for the statistical analysis of upslope flow at BBY vs rain rate at CZD for the 18 of 25 CALJET cases that exhibited an LLJ.*

\begin{tabular}{|c|c|c|c|c|c|c|c|c|}
\hline Event (1997/98) & $\begin{array}{l}\text { Duration } \\
\text { (h) }\end{array}$ & $\begin{array}{c}\text { Mean LLJ } \\
\text { core speed } \\
\left(\mathrm{m} \mathrm{s}^{-1}\right)\end{array}$ & $\begin{array}{l}\text { Height of } \\
\text { mean LLJ (m) }\end{array}$ & $\begin{array}{l}\mathrm{CZD} \\
\text { rainfall } \\
(\mathrm{mm})\end{array}$ & $\begin{array}{l}\text { CZD rain } \\
\text { rate } \\
\left(\mathrm{mm} \mathrm{h}^{-1}\right)\end{array}$ & $\begin{array}{l}\text { BBY } \\
\text { rainfall } \\
(\mathrm{mm})\end{array}$ & $\begin{array}{l}\text { BBY rain } \\
\text { rate } \\
\left(\mathrm{mm} \mathrm{h}^{-1}\right)\end{array}$ & $\begin{array}{c}\text { Rainfall } \\
\text { ratio } \\
\text { (CZD/ } \\
\text { BBY) }\end{array}$ \\
\hline 1900 UTC 24 Nov-2200 UTC 24 Nov & 3 & 14.04 & 842 & 6.54 & 2.18 & 1.26 & 0.42 & 5.19 \\
\hline 0600 UTC 26 Nov-1000 UTC 26 Nov & 4 & 22.34 & 1145 & 19.09 & 4.77 & 6.75 & 1.69 & 2.83 \\
\hline 2100 UTC 29 Nov-2300 UTC 29 Nov & 2 & 14.06 & 943 & 4.00 & 2.00 & 2.50 & 1.25 & 1.60 \\
\hline 2200 UTC 3 Dec-1000 UTC 4 Dec & 12 & 19.65 & 1145 & 11.00 & 0.92 & 8.25 & 0.69 & 1.33 \\
\hline 0800 UTC 7 Dec-1200 UTC 7 Dec & 4 & 12.82 & 1145 & 6.53 & 1.63 & 2.51 & 0.63 & 2.60 \\
\hline 0600 UTC 14 Dec-0800 UTC 14 Dec & 2 & 20.47 & 1246 & 8.26 & 4.13 & 7.00 & 3.50 & 1.18 \\
\hline 0400 UTC 2 Jan-0900 UTC 2 Jan & 5 & 15.40 & 640 & 33.45 & 6.69 & 11.03 & 2.21 & 3.03 \\
\hline 1800 UTC 3 Jan-2300 UTC 3 Jan & 5 & 16.05 & 993 & 12.87 & 2.57 & 0.00 & 0.00 & $\infty$ \\
\hline 0700 UTC $10 \mathrm{Jan}-1100$ UTC 10 Jan & 4 & 12.00 & 1145 & 11.02 & 2.76 & 9.52 & 2.38 & 1.16 \\
\hline 1900 UTC 11 Jan-0100 UTC 12 Jan & 6 & 16.29 & 539 & 69.58 & 11.60 & 11.76 & 1.96 & 5.92 \\
\hline 1000 UTC 14 Jan-2000 UTC 14 Jan & 10 & 15.69 & 1246 & 23.28 & 2.33 & 29.60 & 2.96 & 0.79 \\
\hline 1100 UTC 26 Jan-1400 UTC 26 Jan & 3 & 11.98 & 943 & 9.00 & 3.00 & 1.75 & 0.58 & 5.14 \\
\hline 0300 UTC 29 Jan-0600 UTC 29 Jan & 3 & 25.50 & 741 & 10.06 & 3.35 & 0.25 & 0.08 & 40.24 \\
\hline 1800 UTC 5 Feb-2300 UTC 5 Feb & 5 & 24.51 & 943 & 66.39 & 13.28 & 20.85 & 4.17 & 3.18 \\
\hline 1600 UTC 7 Feb-1800 UTC 7 Feb & 2 & 27.81 & 741 & 16.45 & 8.23 & 10.81 & 5.41 & 1.52 \\
\hline 1900 UTC 12 Feb-2300 UTC 12 Feb & 4 & 18.63 & 1347 & 3.25 & 0.82 & 9.00 & 2.25 & 0.36 \\
\hline 0900 UTC 19 Feb-1400 UTC 19 Feb & 5 & 19.25 & 943 & 53.31 & 10.66 & 13.03 & 2.61 & 4.09 \\
\hline 0900 UTC 23 Feb-1100 UTC 23 Feb & 2 & 19.55 & 1044 & 0.25 & 0.13 & 0.50 & 0.25 & 0.50 \\
\hline Totals & 81 & & & 364.33 & & 146.37 & & 2.49 \\
\hline Avg & & 18.11 & 985 & & 4.50 & & 1.81 & \\
\hline $\begin{array}{l}\text { Percent of } 25 \text {-case winter-season } \\
\text { inventory (see Table } 3 \text { ) }\end{array}$ & 0.17 & & & 0.25 & 1.47 & 0.22 & 1.29 & 1.13 \\
\hline
\end{tabular}

* The LLJ was defined as a max of total wind speed below $1.5 \mathrm{~km}$ MSL residing beneath a local min aloft. This low-level max was required to be at least $2 \mathrm{~m} \mathrm{~s}^{-1}$ larger than the min aloft. At least two consecutive hourly profiles meeting these criteria were required to generate a mean wind profile for each case.

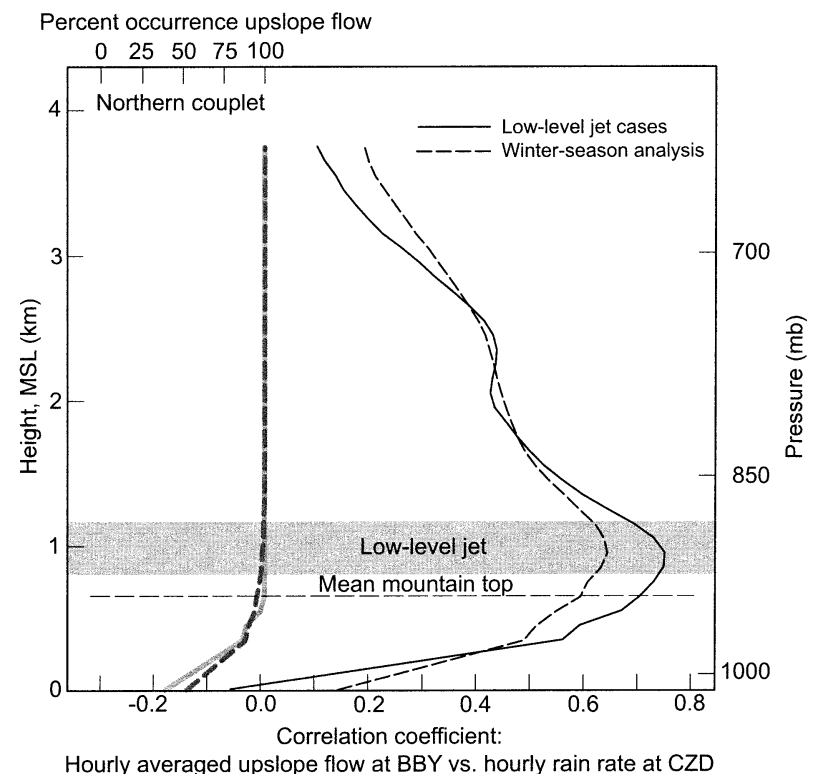

FIG. 16. Vertical profiles of linear correlation coef based on hourly averaged profiles of upslope flow at BBY vs hourly rain rate at CZD for the 18 LLJ cases (solid black) and for the complete 25-case winterseason inventory (dashed black). The vertical profiles of percent occurrence of upslope flow are also shown for the 18 and 25 cases (solid and dashed gray shade, respectively). The shaded region denotes the position of the LLJ. The mean mountaintop height of the neighboring coastal mountains is also shown.
To assess the impact of landfalling LLJs on rain rate in California's coastal mountains, the $81 \mathrm{~h}$ of profiler and rain-rate data from the LLJ inventory at the northern couplet (Table 6) were used to calculate vertical profiles of linear correlation coefficient and linear regression slope for the LLJ environment (Figs. 16 and 17, respectively). The vertical structure of the correlation coefficient profile (Fig. 16) mirrored that of the correlation coefficient profile based on the 468-h winter-season inventory, i.e., a prominent maximum at $0.95 \mathrm{~km}$ MSL at the altitude of the LLJ flanked by much lower values. Companion profiles of percent occurrence of upslope flow were also similar for the LLJ and winter-season inventories. Significantly, the maximum correlation coefficient increased from 0.644 based on the winter-season inventory to 0.751 for the LLJ subsample, thus indicating that the linear relationship between upslope flow and rain rate is more robust in LLJ conditions than for the less restrictive winter-season inventory. The profiles of linear regression slope for the LLJ and winterseason inventories (Fig. 17) show a jet-level maximum of $0.92 \mathrm{~mm} \mathrm{~h}^{-1}\left[\mathrm{~m} \mathrm{~s}^{-1}\right]^{-1}$ for the LLJ subsample that is approximately $50 \%$ steeper than for the winter-season inventory. Because the LLJ inventory yields a substantially more efficient rain-rate response at jet level than the winter-season inventory for a given increase in upslope flow, it is likely that the LLJ environment possessed more favorable thermodynamics (e.g., greater low-level moisture and larger potential instability) that 


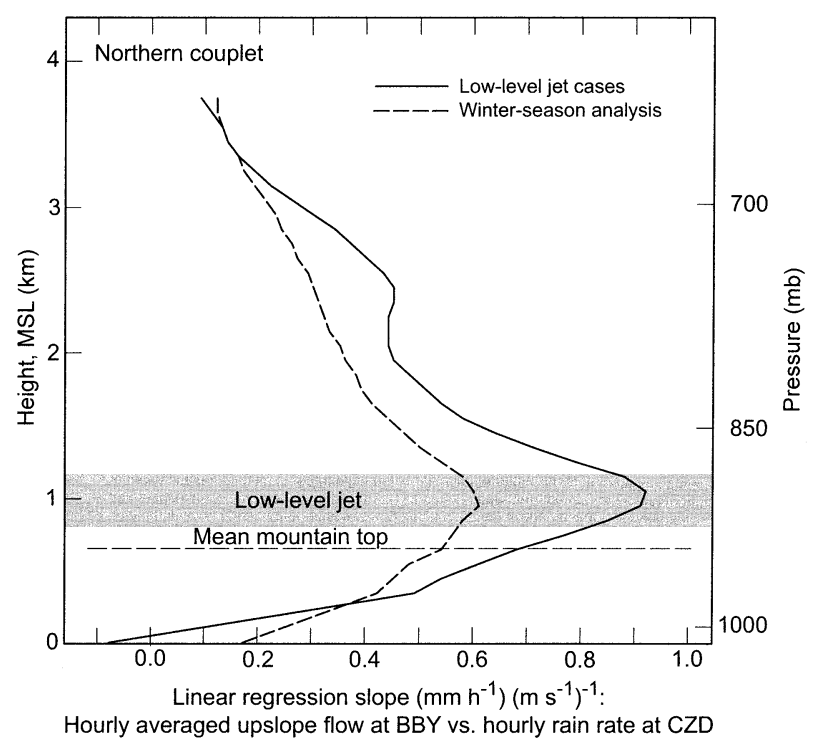

FIG. 17. Vertical profiles of linear regression slope based on hourly averaged profiles of upslope flow at BBY vs hourly rain rate at CZD for the 18 LLJ cases (solid) and for the complete 25-case winterseason inventory (dashed). The shaded region denotes the position of the LLJ. The mean mountaintop height of the neighboring coastal mountains is also shown.

allowed heavier orographic rains to develop and persist over the mountains during periods of enhanced upslope flow. A comparison of average rainfall characteristics between the LLJ and winter-season inventories support this assertion (Tables 3 and 6): the rain rate at CZD was $47 \%$ larger during the LLJ cases and the rainfall ratio between CZD and BBY was 13\% larger.

The orographic rain-rate enhancement at CZD associated with the composite LLJ profile at BBY was estimated, based on the assumption that the composite LLJ and its upslope maximum is a perturbation from a mean state that is devoid of the LLJ. A vertical profile of rainrate enhancement was calculated (Fig. 18) by multiplying the upslope perturbation at each level (Fig. 15) with the LLJ-based linear regression slope at the same altitude (Fig. 17). Because the upslope-flow perturbation is largest at the height of the LLJ and at the height of the steepest regression slope, the orographic rain-rate enhancement is also maximized at the altitude of the LLJ. This is also the altitude where the linear relationship between upslope flow at BBY and rain rate at CZD is statistically most robust. Though the maximum rainrate enhancement of $2.55 \mathrm{~mm} \mathrm{~h}^{-1}$ (Fig. 18) is not exceptionally large, it does represent $57 \%$ of the average rain rate of $4.50 \mathrm{~mm} \mathrm{~h}^{-1}$ at CZD for the LLJ inventory (or a total of $206 \mathrm{~mm}$ of rainfall; Table 6) and $83 \%$ of the average rain rate of $3.07 \mathrm{~mm} \mathrm{~h}^{-1}$ at CZD for the less restrictive winter-season inventory (Table 3). Furthermore, persistent LLJ events can yield significant rainfall amounts. Individual events possessing a much larger LLJ perturbation than the composite can yield much greater rain rates associated with the LLJ. It

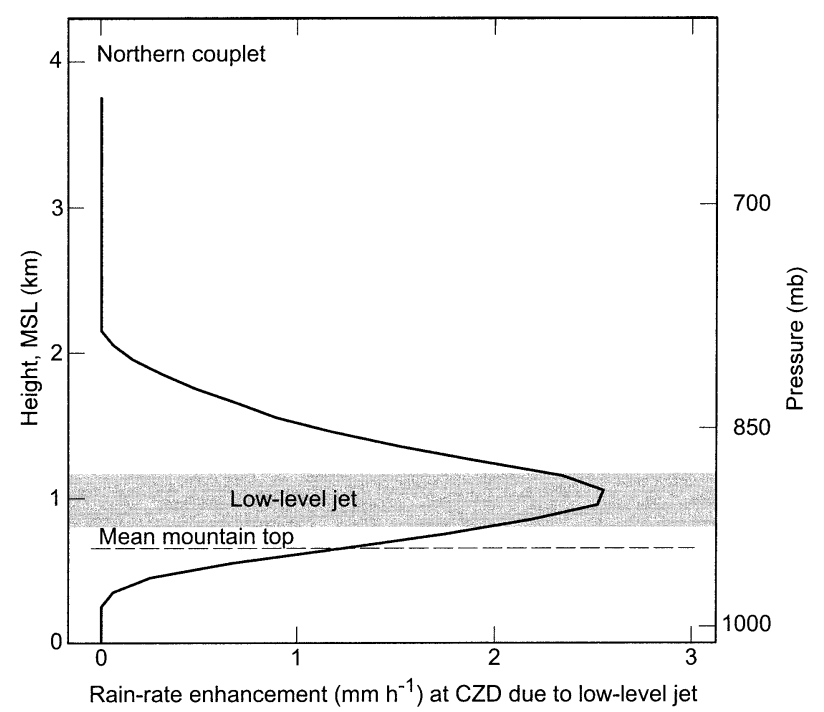

FIG. 18. Vertical profile of rain-rate enhancement at CZD associated with the 18-case LLJ composite at BBY. The shaded region denotes the position of the LLJ. The mean mountaintop height of the neighboring coastal mountains is also shown.

should also be noted that the migration of LLJs into the coastal mountains should provide a temporal increase of upslope flow regardless of the vertical structure of the wind profile, thus yielding an additional rain-rate enhancement, though that topic of research is not covered in this paper. We plan to further explore the relationship between the LLJ environment and orographic rainfall in future research.

\section{Discussion and conclusions}

This observationally based study statistically linked rainfall rates in California's quasi-linear coastal mountains to the upslope component of the flow measured immediately upstream along the coast during the CALJET field program, using hourly averaged rain gauge and wind-profiler data from three observing couplets with differing coastal terrain characteristics. A least squares linear regression fit was applied to time series of upslope flow at each 500-m-thick vertically averaged wind-profiler range gate (and at the surface) and corresponding time series of rain rate measured in the downstream coastal mountains, thus yielding vertical profiles of correlation coefficient $r(z)$ on a case-by-case basis, for the CALJET winter season, and for a composite of LLJ cases. These $r(z)$ profiles extended from the surface upward to $4 \mathrm{~km} \mathrm{MSL}$, well above the highest coastal terrain.

The case-study, winter-season, and LLJ correlation coefficient profiles documented a direct linear relationship between the magnitude of the upslope component of the flow measured by the coastal wind profilers and the magnitude of the rain rate in the downstream coastal mountains. These profiles also pinpointed the layer of 

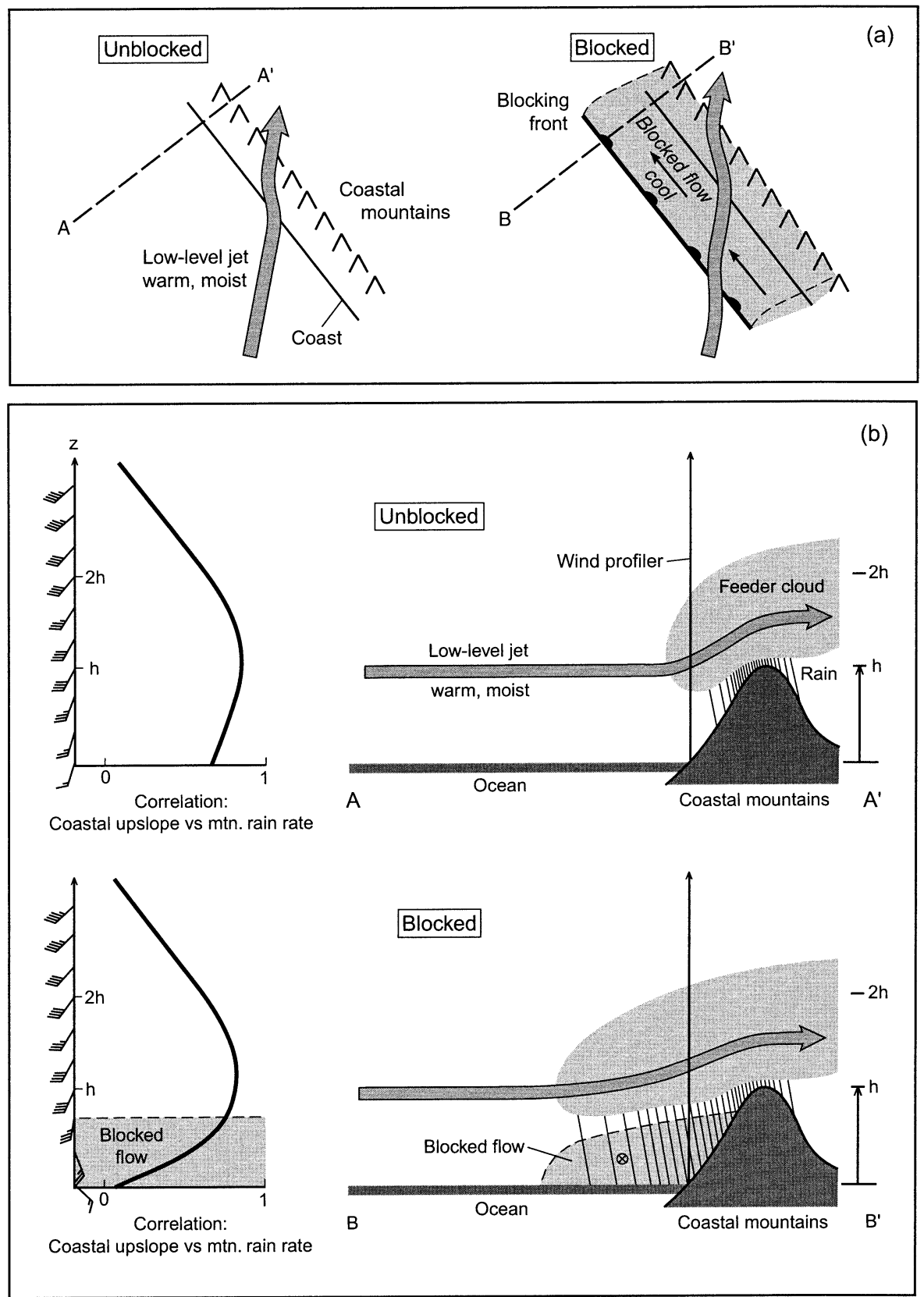

FIG. 19. Conceptual representation of orographic rainfall distribution in California's coastal mountains, and the impact of terrain-blocked flow on this distribution: (a) plan view, and (b) cross-section perspective, with representative coastal profiles of wind velocity (flags and barbs as in Fig. 3) and correlation coef (based on the magnitude of the upslope flow at the coast vs the rain rate in the coastal mountains) shown on the left. The variable $h$ in (b) is the scale height of the mountain barrier. The spacing between the rain streaks in (b) is proportional to rain intensity. The symbol " $\otimes$ " within the blocked flow in (b) portrays a terrain-parallel barrier jet.

upslope flow that is optimally correlated to mountain rainfall. This layer was situated well above the surface, residing near mountaintop and at the altitude of the LLJs $(\sim 1 \mathrm{~km} \mathrm{MSL})$, as is depicted in the conceptual schematic in Fig. 19. It should be noted that this layer is much lower than the level of $700 \mathrm{mb}(\sim 3 \mathrm{~km}$ MSL) used for obtaining the direction of flow in Rhea's (1978) operational orographic precipitation model and lower than the lowest level used to observationally assess the upstream impacts on orographic precipitation in the high Sierra by Pandey et al. (1999). The seven case studies from the three couplets yielded maximum correlation 
coefficients between 0.761 and 0.939 . Alternately stated, $58 \%$ to $88 \%$ of the variation in rain rate during these events was accounted for by a linear relationship with the upslope component of the flow at the height of maximum correlation. These large correlation coefficients provide strong observational evidence that the magnitude of upslope flow played a primary role in generating rainfall in California's coastal mountains on a case-bycase basis, that is, the simple relationship in Eq. (3) was largely applicable for describing the rain rate observed during these cases. In contrast, the maximum correlation near mountaintop for each winter-season profile was such that only $41 \%, 48 \%$, and $31 \%$ of the rain-rate variation was attributable to linear changes in the magnitude of the upslope flow at the northern, central, and southern couplets, respectively. These modest values are not surprising, given that the winter-season composites included cases where upslope forcing was not the dominant mechanism for producing rainfall, that is, the linear relationship between upslope flow and rain rate was modulated significantly by other physical and/or dynamical processes. The variance for the LLJ events was a more robust $56 \%$, thus suggesting that upslope forcing contributed more to the rainfall in LLJ conditions than for the entire winter season. Significantly, the vertical structure of the winter-season and LLJ correlation profiles mirrored that of the case-study profiles. Based on these correlation results, model forecasts of crest-level $(\sim 1 \mathrm{~km})$ winds within storm environments should be monitored closely to assess the likelihood of orographically enhanced rains in California's shallow coastal mountains.

The case-study and winter-season results provide evidence that shallow terrain-blocked flows modulated rainfall in California's coastal mountains (Fig. 19). The case-study results yielded peak correlation coefficients of $0.874-0.939$ and $0.761-0.832$ for unblocked and blocked conditions, respectively. The average rainfall ratio between the mountain and coastal sites for these unblocked and blocked cases was 5.06 and 1.26, respectively. The smaller peak correlation coefficients and average rainfall ratio for the blocked cases suggest that the shallow blocked flows reduced the impact of mountaintop upslope flow on rainfall in the coastal mountains. Because the low-level flow (i.e., below mountaintop) during the blocked cases was oriented roughly parallel to the mountain barrier, the upslope component of the flow in this layer was poorly correlated with rain rates observed in the coastal mountains. From a winter-season perspective, the correlation maximum was largest at the central couplet and smallest at the southern couplet, consistent with the different winter-season rainfall characteristics observed at these couplets. Specifically, the winter-season rainfall ratio between the mountain and coastal sites was largest at the central couplet and smallest at the southern couplet; that is, the central and southern couplets experienced the greatest and least orographic rainfall enhancement in the mountains, respec- tively. The relative absence of low-level blocking at the central couplet (and for the unblocked cases) likely contributed to the largest rainfall ratio and largest correlation maximum, because the low-level upslope flow directly ascended the mountain barrier. Conversely, the prevalence of low-level blocking at the southern couplet (and for the blocked cases) likely resulted in the smallest rainfall ratio and smallest correlation maximum, because isentropic lift occurred over the blocked flow thus producing significant rain at the coast. Interestingly, the winter-season correlation coefficients near mountaintop were largest when rain rates were used from the coastal mountain sites rather than from the coastal sites, thus further highlighting the physical connection between upslope flow and rainfall in the coastal mountains.

A focal point of CALJET's observing strategy was to document the structure and physical processes in the LLJ region ahead of landfalling cold fronts over the eastern Pacific Ocean and along the California coast. This strategy provided the opportunity to explore the physical connection between LLJ structure impacting the coast and orographic precipitation enhancement in the coastal mountains. Landfalling LLJs produced the largest enhancement of upslope flow at jet level, despite the presence of terrain-modified flows below mountaintop during some LLJ events. The steepest increase in rainrate for a given increase in upslope flow (i.e., the steepest regression slope) also occurred at the altitude of the LLJ, as did the largest correlation coefficient. Therefore, the upslope-induced orographic rain-rate response associated with landfalling LLJs was maximized (2.55 $\mathrm{mm} \mathrm{h}^{-1}$ ) and was statistically most robust at the altitude of those LLJs. It should be reiterated that the height of maximum correlation coefficient not only resided at the altitude of landfalling LLJs, but it also corresponded approximately to the top of the coastal terrain. Our study did not resolve the relative contributions of terrain height versus landfalling LLJs to this correlation maximum, and, therefore, it remains a ripe topic for future research.

Acknowledgments. The implementation and success of the CALJET field program was made possible by the dedicated participation of many individuals representing numerous organizations. We are grateful to all of them. Special thanks are given to Clark King and the rest of NOAA/ETL's talented field team for deploying and maintaining the wind profiler network, to Cat Russell for maintaining the profiler's surface meteorological stations and processing the rain gauge data taken from these sites, and to Dan Gottas for meticulously processing the wind profiler data. The offshore composite of LLJs would not have been possible without the exceptional efforts of NOAA's Aircraft Operations Center and the crew of the P-3 aircraft. We are also indebted to The National Biological Service, The University of California at Davis Bodega Marine Laboratory, Robert Mann, and the United States Forest Service for granting 
us permission to deploy and operate the wind profilers at Point Piedras Blancas (PPB), Bodega Bay (BBY), Cazadero (CZD), and Goleta (GLA), respectively. Rob Hartman of the California-Nevada River Forecast Center provided the ALERT rain gauge data, and Jim Adams provided exceptional drafting services. We greatly appreciate the thoughtful comments and suggestions offered by three anonymous reviewers, and by John Brown of NOAA/FSL and Lisa Darby of NOAA/ETL; their insights enhanced the scope and quality of this manuscript. The collection of data and subsequent study presented here were supported by NOAA Research, the Environmental Technology Laboratory, and the U.S. Weather Research Program.

\section{APPENDIX}

\section{Impacts of Vertical and Temporal Averaging on Correlation Coefficient Calculations}

\section{a. Optimizing vertical averaging}

Using hourly averaged, Hann-filtered, wind profiler and rain-rate data from the seven case studies (Table 2), we examine the sensitivity of the maximum correlation coefficient (within each of the seven correlation coefficient profiles) to changes in the vertical averaging resolution or layer-mean thickness of the profiles of upslope flow $U$. The vertical averaging resolution of the $U$ profiles was changed in 100-m increments, from 100$\mathrm{m}$ deep layers (i.e., single range gates) to 1500 -m-deep layers (a vertical average of 15 range gates). For each averaging depth, the $U$ profiles were subjected to overlapping running-mean vertical averages that retained the original $100-\mathrm{m}$ vertical resolution of the wind profiles. Then, for each of the seven case studies, correlation coefficient profiles were calculated using each of the 15 different vertical averages. The stand-alone surface wind data were not included in these running-mean vertical averages. The maximum correlation coefficient from each of these profiles is summarized in Fig. A1.

Other than the outlying case of 5-6 December 1997 from the central couplet, there is not a large sensitivity of maximum correlation coefficient to the layer-mean thickness of the upslope-flow range gates (Fig. A1). An average of the six remaining cases reveals a low-amplitude peak correlation for 500- and 600-m-deep layers. Hence, for this study we appied 500-m-deep, runningmean vertical averages to the profiles of upslope flow, excluding surface data. A 500-m layer is thick enough to remove finescale vertical perturbations and thin enough to retain meaningful vertical structures associated with frontal- and terrain-forced shear layers. The layer averaging also improves upon the mean characterization of the upslope flow while reducing measurement uncertainties. Layer-mean wind velocities that contained a downslope component were excluded from the correlation analysis at that height. Also, the lowest

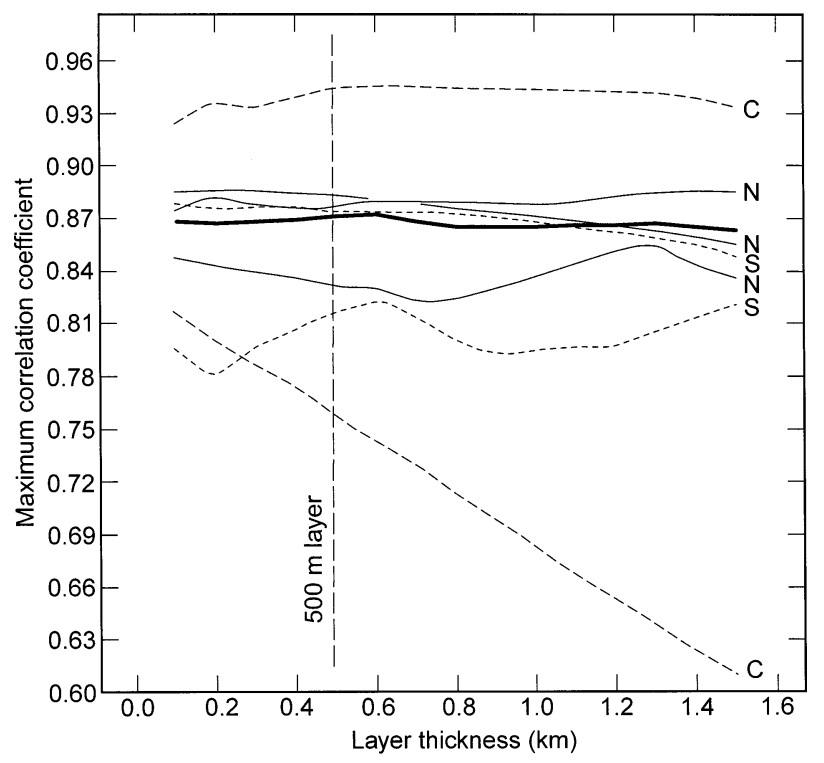

FIG. A1. Sensitivity of the maximum correlation coef to the layer thickness that was applied to the corresponding wind-profiler data. Sensitivities from individual cases (discussed in the text) are shown as thin curves (N, C, and S correspond to cases from the northern, central, and southern couplets, respectively), and the bold solid curve represents an averaged of the six case-specific curves in the top half of the graph.

two range gates at PPB were not included in the 500$\mathrm{m}$ layer-mean averaging because of intermittent seaclutter contamination.

\section{b. Optimizing temporal averaging}

Using data from the northern couplet and guided by the results in section a of the appendix, we used a 500m-deep, layer-mean average of upslope flow between 600 and $1100 \mathrm{~m} \mathrm{MSL}^{\mathrm{A} 1}$ from 11-12 January 1998 (see Table 2) to investigate the sensitivity of the correlation coefficient to changes in the temporal averaging resolution. The northern couplet afforded this opportunity, because the mountain site at CZD had a reliable rain gauge with 2 -min resolution. This exercise also required the use of high-time-resolution (i.e., $\sim 6 \mathrm{~min}$ ) profiler data and the manual editing of these data. Unlike the relatively quick and automated quality control editing employed to obtain hourly averaged wind profiles, the manual editing applied to the 6-min wind profiles was very time consuming. To apply the correlation diagnostic to the high-time-resolution profiler data, the 6min wind profiles could not contain large blocks of spurious data, and these data needed to span a large enough period of time to ensure a statistically significant sample size for averaging periods in excess of $2 \mathrm{~h}$. The case of

\footnotetext{
A1 This layer is slightly above mean mountaintop, and it was chosen because it is the layer where the correlation coefficient between upslope flow and rain rate is nearly maximized (shown in body of text).
} 


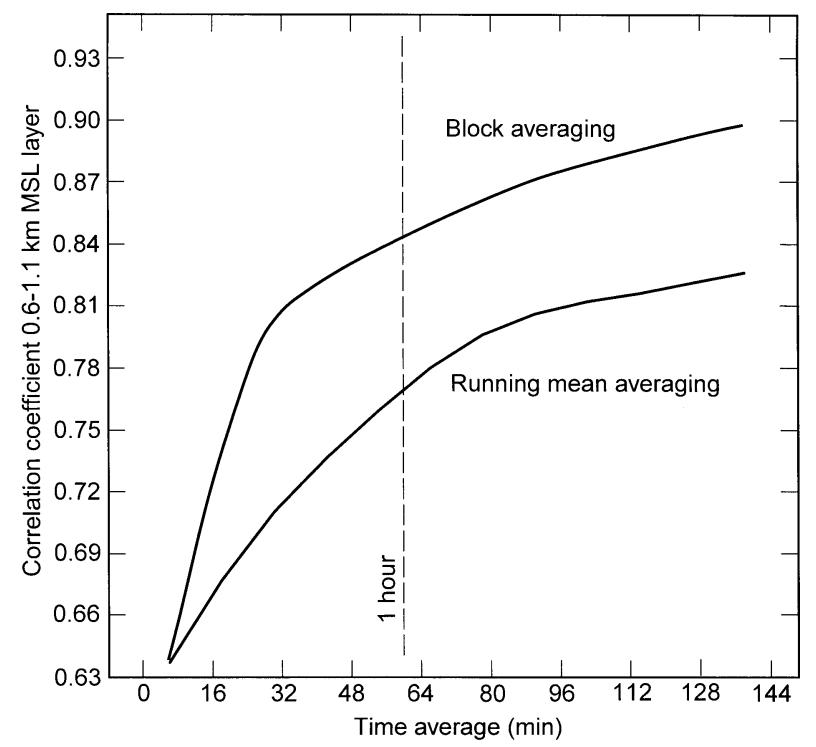

FIG. A2. Sensitivity of correlation coef (in the $0.6-1.1 \mathrm{~km}$ MSL layer) to the time averaged that was applied to wind-profiler and rain gauge data of the northern couplet between 1200 UTC 11 Jan and 2100 UTC 12 Jan 1998. Curves based on the running-mean and blockaveraging techniques are shown.

11-12 January 1998 fit these criteria and has therefore been used.

The sensitivity of correlation coefficient to temporal averaging period was examined using two averaging techniques: the running-mean and block-average techniques. For each averaging technique, the temporal averaging resolution of the upslope-flow (in the 600$1100-\mathrm{m}$ layer) and rain-rate measurements was changed in 12-min increments, from a 6-min period (i.e., temporal averages of 1 and 3 wind-profiler and rain-rate observations, respectively) to a 138 -min period (i.e., temporal averages of 23 and 69 wind-profiler and rainrate observations, respectively). ${ }^{\mathrm{A} 2}$ For the running-mean technique, the data were subjected to overlapping running-mean temporal averages that retained the 6-min resolution of these wind profiles. The block-average technique simply averaged data from adjacent temporal bins that did not contain any overlapping data. The block-average technique has the advantage of mirroring the technique used to calculate the automated hourly wind profiles, though the running-mean technique provides more data points for the correlation calculations. We present the sensitivity of correlation coefficient to temporal averaging period using both techniques (Fig. A2).

The greatest sensitivity of correlation coefficient to temporal averaging period occurs for temporal averages less than $1 \mathrm{~h}$, especially for the block-averaging tech-

\footnotetext{
A2 As with the hourly averaged data, the time series of profiler winds and rain rate based on these subhourly averaged data were subjected to one pass of a 1-2-1 temporal Hann filter.
}

nique. As the temporal averaging period decreases from $1 \mathrm{~h}$, the correlation coefficients degrade rapidly for at least four reasons. First, noise in the data increases for successively smaller averaging periods. Second, finescale features in the upslope flow and rain rate become resolvable, but the upslope flow measured at the coast may not be directly related to the rain rate measured in the downstream coastal mountains. Third, consideration of the advective timescale between the coastal profiler and the mountain rain gauge (e.g., $12.5 \mathrm{~min}$ for $20 \mathrm{~m}$ $\mathrm{s}^{-1}$ flow to advect $15 \mathrm{~km}$ inland) reveals that, for averaging periods of less than about $0.5 \mathrm{~h}$, a time-lag regression likely becomes increasingly important to take into account the propagation of conditions from the coastal profiler to the mountain rain gauge. Fourth, the timescale of microphysical processes that form precipitation and the timescale of its fallout become increasingly important to consider for successively shorter time periods. As the averaging period increases beyond $1 \mathrm{~h}$, then fewer data points are available to perform meaningful correlation analyses; that is, there is a trade-off between optimizing the temporal averaging period and having enough data points for a statistically meaningful correlation analysis. For all averaging periods greater than $6 \mathrm{~min}$, the correlation coefficient is larger for the block-averaging technique than for the running-mean technique. Therefore, based on the results in Fig. A2, we use the routinely available hourly averaged wind profiles for the correlation analyses. The hourly averaging period is also suitable for the temporal sampling of the ALERT rain gauges in the coastal mountains.

\section{REFERENCES}

Alpert, P., 1986: Mesoscale indexing of the distribution of orographic precipitation over high mountains. J. Climate Appl. Meteor., 25, 532-545.

_ precipitation: Numerical study and comparison with precipitation derived from radar measurements. J. Appl. Meteor., 28, 1105-1117.

- , and - 1991: Role of detailed wind-topography interaction in orographic rainfall. Quart. J. Roy. Meteor. Soc., 117, 421426.

Bader, M. J., and W. T. Roach, 1977: Orographic rainfall in warm sectors of depressions. Quart. J. Roy. Meteor. Soc., 103, 269280 .

Bell, G. D., and L. F. Bosart, 1988: Appalachian cold-air damming. Mon. Wea. Rev., 116, 137-161.

Bell, R. S., 1978: The forecasting of orographically enhanced rainfall accumulations using 10-level model data. Meteor. Mag., 107, 113-124.

Bergeron, T., 1965: On the low-level redistribution of atmospheric water caused by orography. Proc. Int. Conf. on Cloud Physics, Tokyo, Japan, IAMAP/WMO, 96-100.

Bougeault, P., and Coauthors, 2001: The MAP special observing period. Bull. Amer. Meteor. Soc., 82, 433-462.

Browning, K. A., 1980: Structure, mechanism, and prediction of orographically enhanced rain in Britain. Orographic Effects in Planetary Flows, R. Hide and P.W. White, Eds., GARP Publication Series, Vol. 23, 85-114.

- F. F. Hill, and C. W. Pardoe, 1974: Structure and mechanism of precipitation and the effect of orography in a wintertime warm sector. Quart. J. Roy. Meteor. Soc., 100, 309-330. 
C. W. Pardoe, and F. F. Hill, 1975: The nature of orographic rain at wintertime cold fronts. Quart. J. Roy. Meteor. Soc., 101, $333-352$.

Carruthers, D. J., and T. W. Choularton, 1983: A model of the feederseeder mechanism of orographic rain including stratification and wind-drift effects. Quart. J. Roy. Meteor. Soc., 109, 575-588.

Colle, B. A., and C. F. Mass, 1995: The structure and evolution of cold surges east of the Rocky Mountains. Mon. Wea. Rev., 123, 2577-2610.

Collier, C. G., 1975: A representation of the effects of topography on surface rainfall within moving baroclinic disturbances. Quart. J. Roy. Meteor. Soc., 101, 407-422.

Colton, D. E., 1976: Numerical simulation of the orographically induced precipitation distribution for use in hydrologic analysis. J. Appl. Meteor., 15, 1241-1251.

Doyle, J. D., 1997: The influence of mesoscale orography on a coastal jet and rainband. Mon. Wea. Rev., 125, 1465-1488.

Dunn, L., 1987: Cold air damming by the Front Range of the Colorado Rockies and its relationship to locally heavy snows. Wea. Forecasting, 2, 177-189.

Ecklund, W. L., D. A. Carter, and B. B. Balsley, 1988: A UHF wind profiler for the boundary layer: Brief description and initial results. J. Atmos. Oceanic Technol., 5, 432-441.

Elliot, R. D., and E. L. Hovind, 1964: The water balance of orographic clouds. J. Appl. Meteor., 3, 235-239.

Gocho, Y., 1978: Numerical experiment of orographic heavy rainfall due to a stratiform cloud. J. Meteor. Soc. Japan, 56, 405-423.

Groisman, P. A., E. L. Peck, and R. G. Quayle, 1999: Intercomparison of recording and standard nonrecording U.S. gauges. J. Atmos. Oceanic Technol., 16, 602-609.

Grossman, R. L., and D. R. Durran, 1984: Interaction of low-level flow with the western Ghat Mountains and offshore convection in the summer monsoon. Mon. Wea. Rev., 112, 652-672.

Heggli, M. F., and R. M. Rauber, 1988: The characteristics and evolution of supercooled water in wintertime storms over the Sierra Nevada: A summary of microwave radiometric measurements taken during the Sierra Cooperative Pilot Project. J. Appl. Meteor., 27, 989-1015.

Hill, F. F., 1983: The use of average annual rainfall to derive estimates of orographic enhancement of frontal rain over England and Wales for different wind directions. J. Climatol., 3, 113-129.

- , and K. A. Browning, 1979: Persistence and orographic modulation of mesoscale precipitation areas in a potentially unstable warm sector. Quart. J. Roy. Meteor. Soc., 105, 57-70.

_, and M. J. Bader, 1981: Radar and rain gauge observations of orographic rain over south Wales. Quart. J. Roy. Meteor. Soc. 107, 643-670.

Jorgensen, D. P., 1984: Mesoscale and convective-scale characteristics of mature hurricanes. Part I: General observations by research aircraft. J. Atmos. Sci., 41, 1268-1285.

, and B. F. Smull, 1993: Mesovortex circulations seen by airborne Doppler radar within a bow-echo mesoscale convective system. Bull. Amer. Meteor. Soc., 74, 2146-2157.

Livezey, R. E., M. Masutani, A. Leetmaa, H. Rui, M. Ji, and A. Kumar, 1997: Teleconnective response of the Pacific-North American region atmosphere to large central equatorial Pacific SST anomalies. J. Climate, 10, 1787-1820.

Lowndes, S., 1968: Forecasting large 24-h rainfall totals in the Dee and Clwyd River Authority Area from September to February. Meteor. Mag., 97, 226-235.

Mendell, T., 1992: Integration of automated hydrological data. Preprints, Conf. on Interdisciplinary Approaches in Hydrology and Hydrogeology, Portland, OR, Amer. Soc. Civil Eng.

Meyers, M. P., and W. R. Cotton, 1992: Evaluation of the potential for wintertime quantitative precipitation forecasting over mountainous terrain with an explicit cloud model. Part I: Two-dimensional sensitivity experiments. J. Appl. Meteor., 31, 26-50.
Myers, V. A., 1962: Airflow on the windward side of a large ridge. J. Geophys. Res., 67, 4267-4291.

NCDC, 1995: Storm Data. Vol. 37, $111 \mathrm{pp}$

NCDC, 1998: Storm Data. Vol. 40, 188 pp.

NOAA, 1982: Storm Data. Vol. 24, 31 pp.

Nordø, J., and K. Hjortnæs, 1966: Statistical studies of precipitation on local, national, and continental scales. Geofys. Publ., 26, 146.

Overland, J. E., and N. A. Bond, 1995: Observations and scale analysis of coastal wind jets. Mon. Wea. Rev., 123, 2934-2941

Pandey, G. R., D. R. Cayan, and K. P. Georgakakos, 1999: Precipitation structure in the Sierra Nevada of California during winter. J. Geophys. Res., 104, 12 019-12 030.

Parish, T. R., 1982: Barrier winds along the Sierra Nevada Mountains. J. Appl. Meteor., 21, 925-930.

Peterson, T. C., L. O. Grant, W. R. Cotton, and D. C. Rogers, 1991 The effect of decoupled low-level flow on winter orographic clouds and precipitation in the Yampa River valley. J. Appl. Meteor., 30, 368-386.

Pierrehumbert, R. T., and B. Wyman, 1985: Upstream effects of mesoscale mountains. J. Atmos. Sci., 42, 977-1003.

Ralph, F. M., and Coauthors, 1998: The use of tropospheric profiling in the California Land-Falling Jets Experiment (CALJET). Proc. Fourth Int. Symp. on Tropospheric Profiling: Needs and Technologies, Aspen, CO, University of Colorado, Boulder, 258-260. and Coauthors, 1999: The California Land-falling Jets Experiment (CALJET): Objectives and design of a coastal atmosphere-ocean observing system deployed during a strong El Nño. Preprints, Third Symp. on Integrated Observing Systems, Dallas, TX, Amer. Meteor. Soc., 78-81.

Rhea, J. O., 1978: Orographic precipitation model for hydrometeorological use. Ph.D. dissertation, Dept. of Atmospheric Science Paper 287, Colorado State University, Fort Collins, CO, 198 pp.

Sawyer, J. S., 1956: The physical and dynamical problems of orographic rain. Weather, $\mathbf{1 1}, 375-381$.

Sinclair, M. R., 1994: A diagnostic model for estimating orographic precipitation. J. Appl. Meteor., 33, 1163-1175.

, D. S. Wratt, R. D. Henderson, and W. R. Gray, 1997: Factors affecting the distribution and spillover of precipitation in the southern Alps of New Zealand-A case study. J. Appl. Meteor. 36, 428-442.

Smith, R. B., 1979: The influence of mountains on the atmosphere. Advances in Geophysics, Vol. 21, Academic Press, 87-230.

, J. Paegle, T. Clark, W. Cotton, G. Forbes, J. McGinley, H.-L. Pan, and M. Ralph, 1997: Local and remote effects of mountains on weather: Research needs and opportunities. Bull. Amer. Meteor. Soc., 78, 877-892.

Smolarkiewicz, P. K., and R. Rotunno, 1990: Low Froude number flow past three-dimensional obstacles. Part II: Upwind flow reversal zone. J. Atmos. Sci., 47, 1498-1511.

Storebø, P. B., 1976: Small scale topographical influences on precipitation. Tellus, 28, 45-49.

Weber, B. L., D. B. Wuertz, D. C. Welsh, and R. McPeek, 1993 Quality controls for profiler measurements of winds and RASS temperatures. J. Atmos. Oceanic Technol., 10, 452-464.

White, A. B., P. J. Neiman, C. King, J. Jordan, F. M. Ralph, and P. O. G. Persson, 1999: Precipitation microphysics observed during the 5-6 February storm of CALJET. Preprints, Third Symp. on Integrated Observing Systems, Dallas, TX, Amer. Meteor. Soc., 91-94.

Yang, D., B. E. Goodison, J. R. Metcalfe, V. S. Golubev, R. Bates, T. Pangburn, and C. L. Hanson, 1998: Accuracy of NWS 8" standard nonrecording precipitation gauge: Results and application of WMO intercomparison. J. Atmos. Oceanic Technol. 15, 54-68.

Yu, C.-K, and B. F. Small, 2000: Airborne Doppler observations of a landfalling cold front upstream of steep coastal oceanography. Mon. Wea. Rev., 128, 1577-1603. 